\title{
¿En dónde combaten los actores armados? Desigualdad de tierras y capacidad estatal en el conflicto armado colombiano
}

\author{
SILVIA OTERO BAHAMÓN**
}

\author{
Artículo recibido: 16 marzo de 2020 \\ Artículo aprobado: 9 de septiembre de 2021
}

Doi: https://doi.org/10.12804/revistas.urosario.edu.co/desafios/a.8818

Para citar este artículo: Otero Bahamón, S. (2022). ¿En dónde combaten los actores armados? Desigualdad de tierras y capacidad estatal en el conflicto armado colombiano. Desafíos, 34(1), 1-45. https://doi.org/10.12804/revistas.urosario.edu.co/desafios/a.8818

\section{Resumen}

Este articulo propone el nuevo concepto de disputa territorial en guerras civiles para preguntarse qué bace un lugar más propenso a ser disputado e indaga por las causas de la disputa territorial en el conflicto armado colombiano. Sugiero que bay una correlación entre la desigualdad de la tierra y la capacidad estatal. Tanto el proceso de producción de desigualdad como la capacidad estatal resultante proveen los motivos, incentivos y oportunidades de la disputa territorial. Testeo mi teoría con una base de datos compuesta por 200 municipios colombianosy un periodo de cinco años. Mis resultados sugieren que la desigualdad de la tierra conduce a mayor capacidad estatal y la capacidad intermedia del

\footnotetext{
* Agradezco al Centro de Investigación y Educación Popular por facilitar los datos para este artículo. Versiones previas del mismo se beneficiaron de generosos comentarios de Jason Seawright, James Mahoney, Víctor Barrera, Fernán González y dos pares evaluadores. Todos los errores e imprecisiones son solo mías.

** Facultad de Estudios Internacionales, Políticos y Urbanos, Universidad del Rosario, Bogotá, Colombia. Correo electrónico: silvia.otero@urosario.edu.co oRCID: https://orcid. org/0000-0002-4514-8514
} 


\title{
2 I Silvia Otero Bahamón
}

estado se correlaciona con la disputa territorial. Los hallazgos de este artículo confirman la existencia de un nexo entre la desigualdad de la tierra y el conflicto en Colombia a través de la capacidad estatal. Este hallazgo tiene implicaciones para la estrategia de expansión de la presencia estatal durante el posconflicto.

Palabras clave: conflicto armado; desigualdad de tierras; capacidad estatal; control territorial; Colombia.

\section{Where do Armed Actors Fight? Land Inequality and State Capacity in the Colombian Civil War}

\begin{abstract}
This article proposes a new concept of territorial dispute in civil wars to ask what makes a place more likely to be contested. It also investigates the territorial dispute causes of the Colombian armed conflict. I suggest that there is a correlation between land inequality and state capacity, and the process of inequality production and its resulting state capacity provide the motives, incentives, and opportunities for territorial dispute. I test my theory with a database composed of 200 Colombian municipalities over a five-year period. My results suggest that land inequality leads to greater state capacity, and intermediate state capacity correlates with territorial disputes. The findings confirm the existence of a nexus between land inequality and conflict in Colombia through state capacity. This has implications for the strategy of expanding state presence during the post-conflict period.
\end{abstract}

Keywords: Civil war; land inequality; state capacity; territorial control; Colombia.

\section{Onde lutam os atores armados? Desigualdade de terras e capacidade estatal no conflito armado colombiano}

\begin{abstract}
Resumo
Onde lutam os atores armados? Este artigo propõe o novo conceito de disputa territorial nas guerras civis para indagar o que torna um lugar mais propenso a ser disputado e investigar as causas da disputa territorial para o conflito armado colombiano. Sugiro
\end{abstract}


que há uma correlação entre a desigualdade fundiária e a capacidade do Estado, e tanto o processo de produção da desigualdade, como sua capacidade estatal resultante, fornecem os motivos, incentivos e oportunidades para a disputa territorial. Eu testo minha teoria com um banco de dados formado por 200 municipios colombianos por um periodo de cinco anos. Meus resultados sugerem que a desigualdade fundiária leva a uma maior capacidade estatal e a capacidade intermediária do estado está correlacionada com a disputa territorial. Os resultados deste artigo confirmam a existência de um nexo entre desigualdade de terras e conflito na Colômbia, mas por meio da capacidade do Estado. Essa descoberta tem implicações para a estratégia de expansão da presença estatal durante o periodo do pós-conflito.

Palavras-chave: conflito armado; desigualdade fundiária; capacidade do Estado; controle territorial; Colômbia.

¿En dónde combaten los actores armados? En guerras civiles donde buscan ganar y expandir el control territorial, ¿en qué lugares se concentran las confrontaciones? ¿Cuáles son las particularidades de los lugares disputados? Una literatura floreciente sobre la dinámica de la guerra civil se ha centrado en las causas del inicio, la duración y la terminación de la guerra civil (Balcells \& Kalyvas, 2014; Collier \& Hoeffler, 2004; Fearon \& Laitin, 2003; Hegre \& Sambanis, 2006; Kalyvas \& Balcells, 2010; Ross 2004; Walter 1997), las interacciones civiles-rebeldes (Arjona, 2016a; 2016b; Mampilly, 2011) y la victimización civil (Humphries \& Weinstein, 2006; Kalyvas, 2006). Sin embargo, se ha dedicado mucho menos esfuerzo a comprender la interacción entre diferentes grupos armados. Stathis Kalyvas (2006), en su ya clásico libro sobre la guerra civil griega, establece que una dinámica muy importante de la guerra civil es el control territorial. En su análisis teórico, el autor establece que el control se puede clasificar en cinco zonas que van desde el control absoluto del estado hasta el control rebelde completo, con áreas disputadas en el medio. Desde entonces, se ha vuelto cada vez más evidente que el control territorial es una característica muy importante en la comprensión de las guerras civiles y se ha dedicado un esfuerzo creciente a medirlo y clasificarlo (Arjona, 2016a; Tao et al., 2016). No obstante, a pesar de la importancia reconocida del control territorial en las dinámicas de las guerras civiles, la cuestión de qué hace que un territorio sea 


\section{4 / Silvia Otero Bahamón}

más susceptible de disputa hasta ahora está empezando a recibir atención teórica y empírica.

Como establece Hammond (2018) en su reciente trabajo, la mayor parte de las investigaciones sobre dónde se concentra la violencia en los conflictos identifica características propias del territorio que los hace objeto de disputa por los actores armados. Estas características tienden a clasificarse en aspectos económicos, políticos o estratégicos. Algunas investigaciones han demostrado correlación entre lugares con depósitos de diamantes, madera o petróleo y la concentración allí de eventos violentos (Buhaug et al., 2009; Gilmore et al., 2005; Rustad et al., 2008). En el mismo sentido, Hegre et al. (2009) establecen que la violencia en los conflictos tiende a aglomerarse alrededor de las zonas más ricas. Por otro lado, no solo los recursos económicos hacen que un territorio se vuelva estratégico para los actores armados en disputa (Weinstein, 2006); el político es otro recurso en disputa: los actores armados dependen de la colaboración de los civiles, especialmente donde puedan capitalizar los agravios de la población civil. Es por esto que Raleigh y Hegre (2009) encuentran que los eventos de conflicto se concentran en lugares con alta densidad poblacional alejados de la capital, así como Buhaug et al. (2011) establecen que la violencia se concentra en lugares con alta densidad poblacional y bajo desarrollo económico. Finalmente, otros territorios tienen características estratégicas que van más allá de los recursos políticos o económicos que albergan que los hacen atractivos para los actores en disputa. Por ejemplo, las retaguardias de los rebeldes y los lugares centrales del control del estado son lugares en los que podría producirse una disputa territorial si el equilibrio de poder se inclina a favor de uno u otro (Boulding, 1962; Tollefsen \& Buhaug, 2015). Trabajos como los de Zhukov (2012) y Hammond (2018) han identificado que lugares ubicados estratégicamente en la red de carreteras tienden a concentrar eventos violentos porque dan acceso a otros nodos. En la misma línea, Raleigh y Hegre (2009) encuentran que hay una mayor posibilidad de conflicto en lugares con carreteras primarias que secundarias y terciarias, esto evidencia que el conflicto ocurre donde fuerzas rebeldes y estatales pueden encontrarse, probablemente gracias al acceso que da una carretera. 
Este trabajo construye sobre esta reciente agenda investigativa para aportar tres contribuciones: una conceptual, una teórica y una empírica. Si bien los estudios mencionados anteriormente preguntan por qué algunas locaciones concentran violencia, estos no especifican si dicha violencia viene de uno o varios actores armados; en otras palabras, no tienen en cuenta la interacción entre los actores en disputa. La violencia puede ser intensa y provenir de un solo bando. Mi concepto de disputa territorial corrige estas falencias, operacionalizándolo de tal modo que tiene en cuenta la interacción entre los grupos armados. La contribución teórica se desarrolla a partir de la historiografía existente sobre el conflicto armado colombiano. Desde ella, ofrezco una teoría exploratoria sobre dónde se concentra la disputa territorial de los actores armados. Esta teoría es novedosa en tanto se construye con la interacción de factores políticos y estratégicos del territorio, en vez de tomarlos por separado.

En concreto, mi objetivo en el artículo es establecer que la desigualdad de la tierra y la capacidad del estado interactúan para hacer de una localidad más propensa a albergar disputas territoriales entre los actores armados. Esto hipotéticamente se produciría a través de varios canales. Primero, cuando se produce desigualdad de la tierra los grupos rebeldes podrían explotar allí más fácilmente los agravios de los campesinos despojados. Así mismo, los actores de la sociedad civil que tienen tierras en sitios donde ha aumentado recientemente la desigualdad necesitarían la protección de otros actores armados o del estado para asegurar sus derechos de propiedad. En otras palabras, el proceso de acumulación de tierras llevaría a que en un mismo territorio coincidan intereses que pueden ser capitalizados por distintos actores armados, haciendo más probable la disputa en dicho territorio.

En segundo lugar, como lo han establecido varios autores (Duncan, 2015; González, 2014; Reyes, 1978; Ocampo, 2007; Vásquez, 2018), la producción de desigualdad de tierras a menudo va de la mano con incrementos en la capacidad local del estado porque la concentración de tierras se asocia con la creación de élites que buscan mercados para los productos agrícolas y ganaderos, que aumenta la importancia 


\section{6 / Silvia Otero Bahamón}

económica y política de algunas áreas. Esta “integración territorial” por la vía de la concentración de la propiedad conlleva — según los casos estudiados por los autores en Córdoba, Caquetá y Sucre, entre otros-, a una mayor presencia del estado a través de redes políticas, instituciones e infraestructura. Ahora bien, mi estudio teoriza que dicha capacidad estatal intermedia que caracterizaría los lugares donde ha aumentado la desigualdad de la tierra favorecería la disputa territorial por razones estratégicas. Por un lado, los lugares con capacidad estatal intermedia contendrían un valor estratégico tanto para el estado como para los rebeldes. Para los rebeldes, disputar el control en áreas con capacidad estatal intermedia sería un paso hacia el control total del país, mientras para el estado sería necesario mantener el control en áreas con capacidad estatal intermedia para obstaculizar la expansión de los rebeldes. ${ }^{1}$ Por otro lado, en lugares donde la capacidad del estado es intermedia, tanto los rebeldes como el estado tienen suficiente capacidad coercitiva para luchar. Los rebeldes serían fácilmente superados en lugares con presencia superior del estado, y el estado puede perder fácilmente en lugares donde su presencia es muy débil. En conclusión, las zonas de presencia intermedia estatal producirían una combinación de factores políticos y estratégicos que las harían propensas a la disputa territorial en el marco del conflicto armado. La disputa territorial rara vez ocurriría en áreas donde el estado es muy fuerte o muy débil.

Para probar esta teoría y otras explicaciones rivales, realicé un análisis cuantitativo de una muestra representativa de municipios colombianos durante 5 años de conflicto intenso (2000-2004). Colombia es un buen lugar para probar teorías sobre disputas territoriales porque es un país con una guerra civil prolongada, que ha durado más de 50 años y se dispone de datos de buena calidad para el nivel subnacional. El periodo seleccionado se identifica como aquél en el que ocurrió la lucha más intensa. Durante esos años, tanto los grupos rebeldes como los grupos paramilitares se expandieron por todo el país, y no era claro quién tenía la ventaja. A veces parecía que las guerrillas ganarían la guerra, y a veces parecía que el estado ganaría (Granada

\footnotetext{
1 Esta noción de niveles intermedios es la que inspira la teoría de Hammond (2018) en su análisis de la red de carreteras.
} 
\& Sánchez-Merteens, 2009; Grupo de Memoria Histórica, 2013). Los resultados empíricos de este artículo dan indicios para creer que existe una relación entre la desigualdad de la tierra y los niveles intermedios de la capacidad estatal, y que estos a su vez aumentan las probabilidades de disputa territorial.

Aunque centrado en la guerra civil colombiana, este artículo proporciona un marco conceptual y una teoría que podría testearse en otros contextos. Para los países con una guerra civil prolongada como Colombia, es importante saber dónde es probable una disputa territorial y cuáles son las características de los sitios que concentran las hostilidades de varios actores armados. Si bien la relación entre desigualdad rural y formación estatal pueda ser específica al caso colombiano, el impacto de la capacidad estatal intermedia en la disputa territorial puede viajar a otros conceptos de guerras irregulares. Este artículo ofrece una exploración que invita a futuras investigaciones en la materia.

\section{¿Qué es la disputa territorial?}

Figura 1. Escenarios de expansión del control territorial

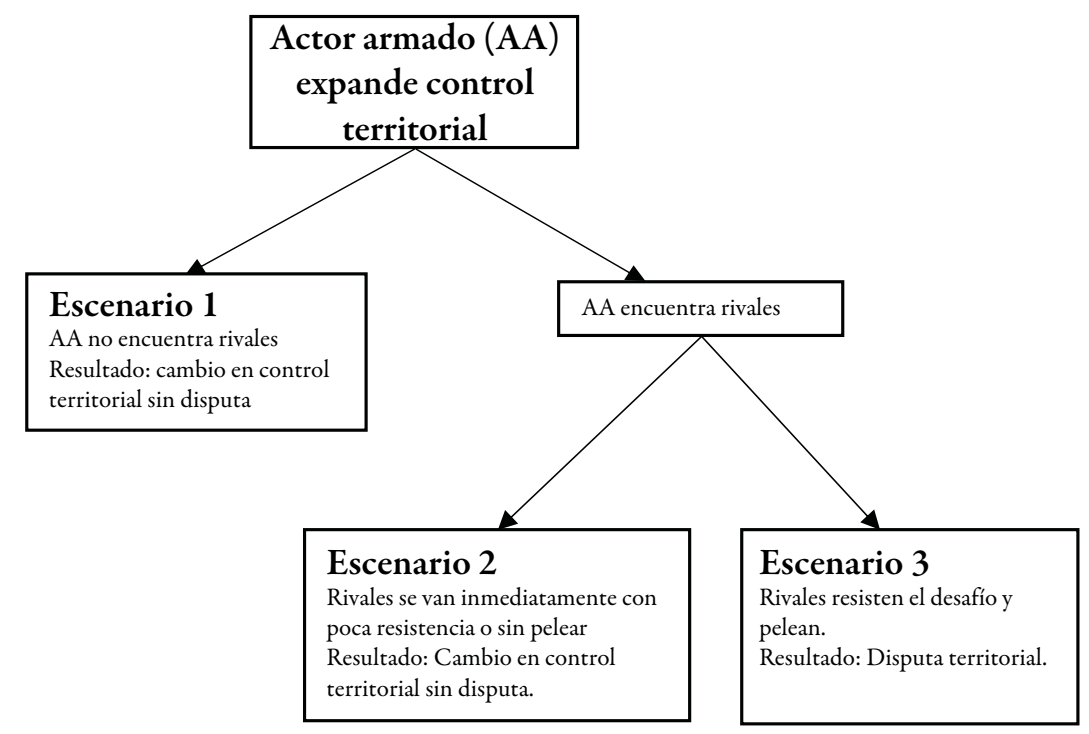

Fuente: elaboración propia. 


\section{8 / Silvia Otero Bahamón}

En el proceso de expandir su control territorial, los actores armados podrían (a) no encontrar rivales (escenario 1) o (b) encontrar rivales. Si se produce la última condición, el rival tiene dos opciones: puede huir y dejar la zona a los retadores (escenario 2), o puede participar en la lucha contra los retadores (escenario 3). En este artículo me centraré en el escenario 3 que llamo disputa territorial. Contestaré la siguiente pregunta: ¿Dónde es más probable que ocurra una disputa territorial? $\mathrm{O}$, en otras palabras, ¿qué explica la distribución geográfica de la disputa territorial?

En el contexto de las guerras civiles, la disputa territorial es una situación en la que dos o más actores armados (como rebeldes, estado, grupos de autodefensa, mafias, carteles, milicias) luchan por controlar un territorio. Este trabajo se enfocará en disputas territoriales a nivel municipal.

Para que un territorio sea disputado, deben existir dos condiciones necesarias y conjuntamente suficientes (Goertz, 2006). Primero, el retador debe intentar obtener el control del territorio $\mathrm{X}$, que está en manos del controlador. En segundo lugar, el controlador debe intentar mantener el control territorial de X. Como se muestra en la figura 1, la disputa territorial no es lo mismo que un cambio en el control territorial. Los territorios pueden cambiar de manos sin incurrir en disputas territoriales (escenarios 1 y 2), y una situación de disputa territorial puede no conducir a un cambio de control si el controlador gana la confrontación. Aunque la disputa territorial es una dinámica de guerra civil que produce altos niveles de violencia, esta no ha sido tratada como una variable dependiente distinta de los cambios en el control territorial entre los actores armados.

Con respecto a la literatura de la guerra civil colombiana, no existen análisis estadísticos previos que consideren la disputa como el fenómeno a explicar. La mayoría de los análisis explican la presencia, los órdenes políticos, la expansión y la violencia de los actores armados contra la población civil (Arjona, 2014; Bottia, 2003; Sánchez \& Chacón, 2006; Vélez, 2001). 


\section{El argumento: desigualdad de la tierra y capacidad estatal}

Como ya se estableció, aunque la disputa territorial es una dinámica de guerra civil que produce altos niveles de violencia, esta no ha sido tratada como una variable dependiente distinta de los cambios en el control territorial entre los actores armados. ¿Qué hace que un lugar tenga más probabilidad de ser disputado?

Como Cramer (2005) resume:

$[\ldots]$ es casi un presupuesto universal que una distribución desigual de los recursos y la riqueza provocará una rebelión violenta. Y, sin embargo, es tan obvio e históricamente establecido que una distribución de los ingresos y la riqueza fuertemente sesgada no siempre o incluso generalmente no conduce a la rebelión. (p. iii)

Los agravios basados en la desigualdad pueden ser producidos por una distribución desigual del ingreso, la concentración de la tierra y la pobreza. Sin embargo, su vínculo con la violencia ha sido ampliamente debatido. Diferentes estudios han encontrado una falta de vínculo entre la desigualdad y la violencia, una relación lineal o una relación en forma de U. ${ }^{2}$ Parte del debate tiene que ver con la unidad de análisis seleccionada. Mientras que Collier (2000a; 2000b) argumentó en contra del papel de la desigualdad, la pobreza y los agravios en el inicio de la guerra civil, Cramer (2005) y Østby (2013) sugirieron que el vínculo entre desigualdad y conflicto no debe probarse a nivel nacional, con coeficientes de Gini y regresiones entre países. En cambio, están a favor de bajar la escala del análisis para mirar los niveles subnacionales y utilizar medidas de desigualdad distintas.

La desigualdad de la tierra ha sido especialmente importante en la rebelión en El Salvador, Nicaragua y Mozambique (Cramer, 2005, p. 13). En el contexto colombiano, los académicos nacionales han

2 Para un resumen de estos debates ver Cramer (2005). 
alcanzado un consenso sobre la importancia de la desigualdad de la tierra en diferentes dinámicas de conflicto (González et al., 2003; Museo Casa de la Memoria \& Reyes, 2019; Saffon \& Sánchez, 2019; Vásquez et al., 2011). Esta conexión tiene diferentes manifestaciones. Primero, el acaparamiento de tierras condujo al desplazamiento forzado de campesinos que se organizaron en grupos de autodefensa que luego se convirtieron en las FARC (Fuerzas Armadas Revolucionarias de Colombia), la guerrilla colombiana más importante. En segundo lugar, la falta de una reforma agraria ha agudizado la falta de tierras para las nuevas generaciones de campesinos, lo que incentiva la colonización de tierras periféricas para la producción de cultivos de coca. La producción de coca y cocaína alimenta las finanzas de los rebeldes, y la masa de cocaleros constituye una base importante de apoyo de diferentes grupos armados (Ciro, 2019; Peñaranda-Currie et al., 2021; Vásquez, 2018). Tercero, los ingresos exorbitantes de la producción de cocaína llevaron a los capos de la droga a comprar tierras para blanquear dinero, lo que condujo a una contrarreforma agraria. Cuarto, los autores identifican en el choque entre la agricultura comercial y la agricultura campesina el surgimiento de grupos paramilitares (Duncan, 2015; Gonzalez et al., 2003). A pesar de que el nexo entre desigualdad de la tierra y conflicto en la literatura colombiana actual ya ha sido demostrado, la relación entre la desigualdad de la tierra y la disputa territorial sigue sin explorar.

Con relación específica a la pregunta por la disputa territorial, Vásquez et al. (2011) y González (2011) sugieren que en Colombia la expansión de las tierras para la cría de ganado y la agricultura comercial en las llanuras ha provocado la expulsión de las poblaciones campesina e indígena, que se vieron obligadas a establecerse en las montañas. Esta producción de desigualdad a través de la expansión de las fincas creó un antagonismo de clases que facilitó la inserción de grupos rebeldes en las montañas y la creación de grupos paramilitares en las llanuras (González, 2010, p. 438; Reyes, 1978).

De esta descripción se podría deducir que la disputa territorial es un producto de los agravios producidos por la concentración de la tierra. Sin embargo, como han argumentado varios académicos, uno no 
puede asumir una relación automática entre los agravios basados en la desigualdad y el conflicto (Van Leeuwen \& Van Der Haar, 2016). Como escribe $Ø$ stby (2013), desde el principio los estudiosos de los movimientos sociales como los de Tilly y Snyder:

[...] rechazan las hipótesis de las explicaciones de los agravios por la razón de que la desigualdad y el descontento están más o menos presentes en prácticamente todas las sociedades (véase también Skocpol, 1979). Por lo tanto, creen que los factores explicativos más directos e influyentes no son las quejas percibidas, sino más bien las oportunidades financieras y políticas para movilizar una organización rebelde. (p. 209)

Østby (2013) agrega: "está claro que los agravios colectivos no conducen automáticamente a acciones violentas. Sin recursos y organización, los agravios como tales pueden hacer poco para desafiar a los defensores poderosos del statu quo (Tilly, 1978)" (p. 216). Van Leeuwen y Van Der Haar (2016), por otro lado, complementan este aspecto, estableciendo que hay poco desarrollo teórico sobre el nexo entre violencia y conflicto agrario. En este sentido, los autores piden que se aclaren varias preguntas:

¿Cómo se vuelven violentos los conflictos locales por la tierra? ¿Cuál es el papel de la agitación social a mayor escala en las disputas locales por la tierra? ¿Cómo pueden los agravios en torno a la tierra servir de caldo de cultivo para la violencia a mayor escala? Y, ¿cómo se conectan las disputas locales por la tierra con patrones más amplios de conflicto en la sociedad? (Van Leeuwen \& Van Der Haar, 2016, p. 95)

En línea con estas preguntas, teorizo que no es la desigualdad de la tierra en sí misma lo que produce el conflicto, sino que la manifestación institucional de dicha desigualdad hace posible la coincidencia geográfica de factores políticos y estratégicos en ciertas localidades. Desarrollo el argumento en dos pasos. Primero, sostengo que la producción de desigualdad de la tierra va de la mano con incrementos en la capacidad del estado; segundo, una capacidad estatal intermedia 


\section{2 / Silvia Otero Bahamón}

está correlacionada con la disputa territorial. La relación entre capacidad estatal intermedia y disputa se daría por dos razones: porque en lugares con ese nivel de capacidad se cristalizarían los agravios de la producción de desigualdad de la tierra y porque ese tipo de capacidad hace de los territorios lugares estratégicos para rebeldes y estado.

Con respecto al primer paso, los académicos colombianos han descubierto que el proceso de concentración de la tierra en varias regiones del país (Costa Caribe, Valle del Cauca, Huila, Tolima) va de la mano con la inclusión de estas regiones en el mercado nacional y las redes políticas de la nación (Aponte, 2019; González, 2014; Ocampo, 2007; Pecaut, 2001; Reyes, 1978; Vásquez, 2018). Como explican dichos autores, estas áreas concentraron la tierra porque estaban desarrollando economías comerciales de agricultura y ganadería. Estas nuevas economías formaron élites políticas y económicas que vincularon estas regiones con el mercado nacional y las instituciones estatales. De los estudios cualitativos de dichos autores se podría deducir que a medida que la tierra se concentra, estas áreas pasaron de niveles de estado bajos a intermedios y a veces altos. Frente al segundo paso, establezco que los lugares con capacidad estatal intermedia serían más propensos a ser disputados no solo porque allí coinciden los motivos de lucha — los agravios por la desigualdad de la tierra-, sino porque son estratégicos para los distintos actores armados.

¿En qué sentido son territorios estratégicos? ¿Por qué los rebeldes y el estado quieren ganar o mantener el control de áreas con capacidad estatal intermedia? En las guerras irregulares, el objetivo final de la mayoría de los grupos rebeldes es obtener el control del estado central (Hammond, 2018). En este sentido, las regiones con capacidad estatal intermedia pueden ser un paso hacia este objetivo final porque albergan un valor estratégico. Cuando un grupo insurgente controla una zona de mediana capacidad estatal, envía una señal de su propia fortaleza y pone en evidencia la incapacidad de su contrincante para proteger a sus ciudadanos. Como establece Hammond (2018): 
[...] los ataques exitosos en lugares políticamente importantes no solo son herramientas útiles de reclutamiento, sino que también sirven para intimidar a los partidarios del enemigo y erosionar el apoyo del Estado al señalar que el gobierno no puede defenderse a sí mismo o a la población civil en su propio patio trasero. (p. 34)

Del mismo modo, quieren mantener el control de las regiones de capacidad estatal intermedia porque estarían interesados en obstaculizar y prevenir la expansión de los rebeldes. Como las regiones de capacidad estatal intermedia son un paso hacia el control del estado central, el estado estaría interesado en evitar que esto suceda.

Otro aspecto estratégico de los territorios con capacidad estatal intermedia es que en estos lugares tanto los rebeldes, las fuerzas estatales y los paramilitares tendrían la capacidad de luchar, puesto que son lugares donde los actores podrían proyectar su fuerza. En el caso de los rebeldes, en lugares donde el estado es fuerte, disuadirán a los rebeldes de disputar. Si es demasiado débil, el control cambiará sin disputa. Pero donde el estado no es fuerte ni débil, donde tiene una capacidad estatal intermedia, habría una oportunidad para disputas territoriales. En el caso de las fuerzas estatales, luchar contra el control rebelde en territorios de baja capacidad estatal sería costoso y tácticamente difícil, especialmente cuando los rebeldes se han expandido a áreas más integradas en las que tienen más incentivos para obtener y proteger.

En resumen, la hipótesis de este trabajo es que la desigualdad de la tierra produciría una capacidad estatal intermedia que a su vez aumentaría la probabilidad de disputa territorial. Esto sucede por (a) los agravios producidos en el proceso de expansión de la tenencia de la tierra, (b) el valor estratégico de las regiones de capacidad estatal intermedia en las estrategias militares más amplias de los actores, y (c) el hecho de que las regiones con capacidad estatal intermedia proporcionan capacidad creíble para luchar por ambas partes. 
En concreto, mi argumento puede resumirse en las dos hipótesis siguientes.

H1: La desigualdad de la tierra está positivamente correlacionada con la capacidad del estado.

H2: La mayor desigualdad de la tierra en contextos de capacidad estatal intermedia está correlacionada con una mayor probabilidad de disputa territorial.

De la discusión anterior, uno puede plantear la primera explicación alternativa.

H3: La desigualdad de la tierra por sí sola hace más probable la disputa territorial.

\section{Alcances y limitaciones de la teoría}

Incluso si la guerra civil colombiana es particular, existen razones para creer que los hallazgos de este artículo pueden ser aplicables a otras guerras civiles. Las conclusiones de este documento podrían ser particularmente relevantes para los conflictos en los que (a) los actores armados luchan por el control del estado central, (b) los conflictos civiles son prolongados y muy activos, y (c) ocurren en estados no fallidos. En este tipo de conflictos los insurgentes pueden expandirse desde sus santuarios, pero tienen dificultades para ganar el poder central del estado. Del mismo modo, los estados tienen la capacidad de combatirlos, pero la prolongación del conflicto implica que no han sido capaces de triunfar.

Con respecto a la literatura sobre conflictos de Colombia, es posible argumentar que los resultados de este análisis también son válidos para diferentes momentos de guerra no incluidos en la muestra. Algunos podrían argumentar que a medida que cambia el equilibrio de poder en una guerra civil, la localización de la disputa también debería variar. Aunque esta idea es correcta en principio, la selección cuidadosa de los años incluidos en mi muestra me permite confiar en 
la validez temporal de mis hallazgos. Granada y Sanchez-Merteens (2009) muestran la evolución del equilibrio de poder en la guerra civil colombiana, utilizando un indicador de equilibrio de poder para cada localidad colombiana. Estos autores encontraron que en los años incluidos en mi análisis se produce un cambio importante: de 1997 a 2000 el equilibrio de poder se inclina hacia el lado rebelde, y desde 2001 en adelante las fuerzas militares toman la iniciativa en acciones violentas unilaterales (Granada \& Sánchez-Merteens, 2009, p. 252). Sin embargo, en el periodo que estudian (1997-2008) ningún actor armado había logrado superar realmente a sus retadores. Se podría concluir que los años incluidos en este análisis me permiten controlar por cambios en el equilibrio de poder, pero no por derrota militar de uno de los actores en conflicto.

\section{Explicaciones alternativas}

El hecho de que la disputa territorial no haya sido tratada como una variable dependiente específica en estudios previos no significa que no existan posibles explicaciones. De hecho, es posible aprovechar los debates existentes en los estudios colombianos e internacionales para formular explicaciones alternativas de las disputas territoriales. En los siguientes párrafos, elaboro una lista de hipótesis alternativas que abordaré en la parte del desarrollo de la teoría que propongo en este artículo.

\section{Disputa territorial como resultado de la competencia de recursos}

Los recursos son importantes para cualquier actor armado. Ya sea motivada por ganancias privadas o no, una organización armada necesita armas, alimentos, equipo y dinero. Metelits (2009) argumenta que "los recursos también incluyen bienes no materiales que pueden producir artículos materiales, por ejemplo, el apoyo popular de la población civil”' (p. 187). Weinstein (2006) distingue entre dotaciones económicas y sociales. Estas diferenciaciones buscan tener en cuenta que las dotaciones económicas, como los recursos naturales, no están presentes en todos los entornos de conflicto. Sin embargo, en los casos en que están presentes, como en el caso colombiano, esperaríamos que 


\section{6 / Silvia Otero Bahamón}

los actores armados compitieran por acceder a ellos o por bloquear el acceso de otros a ellos.

Para la guerra civil colombiana, la cuestión de los bienes saqueables se ha relacionado con los cultivos de coca (Vásquez et al., 2011), minerales como el oro y las esmeraldas (Rettberg \& Ortiz-Riomalo, 2016), regalías de la extracción de recursos naturales (Peñate, 1999) y las transferencias del gobierno central al gobierno local (Sánchez \& Chacón, 2006). De hecho, varios autores han encontrado en análisis estadísticos una conexión entre diferentes tipos de recursos y la expansión de actores armados (Bottia 2003; Sánchez \& Chacón, 2006; Vélez, 2001). En conclusión, uno puede esperar que la presencia de cultivos de coca, regalías y transferencias incrementen el valor estratégico de un territorio, lo que lleva a una disputa territorial.

H4: La presencia de cultivos de coca u otras materias primas (commodities), regalías y transferencias está correlacionada con una mayor probabilidad de disputa territorial.

\section{Disputa territorial como resultado de la falta de instituciones}

Una explicación alternativa de la disputa territorial se relaciona con la ausencia de instituciones estatales para la resolución de conflictos y la prestación de servicios. Varios mecanismos podrían vincular la baja presencia/capacidad estatal con la disputa territorial. Primero, diferentes grupos buscan llenar el vacío de regulación dejado por las instituciones ausentes; segundo, la no aplicación de la ley disminuye los costos del comportamiento ilegal (Echandía, 1998), y tercero, la ausencia de bienes públicos y servicios sociales genera resentimiento popular y actividades rebeldes (Sánchez \& Chacón, 2006, p. 368). Como resultado de estos mecanismos causales, varios grupos armados son empujados hacia áreas de baja presencia estatal.

Estudiosos del conflicto como María Alejandra Vélez (2001) han encontrado un vínculo entre la presencia de grupos rebeldes y servidores públicos. Otros han mencionado que la expansión de los problemas del narcotráfico se explica por un aparato judicial corrupto e ineficiente (Montenegro \& Posada, 1995; Kalmanovitz, 2001; Rubio 
et al., 2002). Si se encuentra evidencia a favor de esta hipótesis, mi teoría propuesta en este artículo sería errónea. Como dije anteriormente, mi hipótesis es que la baja capacidad estatal es un mal predictor de disputas territoriales.

H5: La baja capacidad estatal está correlacionada con una mayor probabilidad de disputa territorial.

\section{Disputa territorial como resultado de la disfunción social a la Huntington}

Vinculado a la explicación anterior, académicos colombianos han propuesto una teoría de disputa territorial similar a la de Huntington (1968) relacionada con los conflictos sociales derivados de transformaciones rápidas. Según Echandía (1999) y Pécaut (2001), el rápido crecimiento económico en ciertas regiones colombianas atrajo una fuerza laboral inmigrante que creó desempleo, reforzó la desigualdad de ingresos y derivó en comportamientos delincuenciales. Este desequilibrio no fue igualado por las instituciones adecuadas, lo que resultó en la necesidad de medios privados para resolver los conflictos. En este contexto, los grupos armados (guerrillas y paramilitares) encontraron su camino para arraigarse en la sociedad explotando la provisión de justicia. "En estas regiones —argumenta Echandía (1999) — no ha sido posible establecer firmemente una base jurídica e institucional que establezca claramente las reglas del juego y ayude a neutralizar la acción violenta de los diferentes actores armados en competencia” (p. 156).

Esta explicación alternativa propondría que las regiones que enfrentan un rápido crecimiento económico y de migración son fuentes de conflictos sociales, donde en ausencia de instituciones estatales y agencias para la aplicación de la ley, estos conflictos atraen a diferentes grupos armados que buscan llenar el vacío de la provisión de justicia. La coexistencia de varios grupos en el mismo territorio conduce, a su vez, a disputas territoriales.

H6: El rápido crecimiento económico y migración están correlacionados con un aumento en la probabilidad de disputas territoriales cuando no existen instituciones estatales fuertes. 
Conflicto territorial como resultado de los ataques a las retaguardias de los rebeldes

Esta explicación se basa en la teoría de que la disputa territorial puede ocurrir en las áreas de un país donde los rebeldes tienen sus santuarios y fortalezas. En los casos en que el estado no falla o se derrumba, el estado intentará disminuir el control insurgente sobre estas áreas. En su famoso artículo, Fearon y Laitin (2003) plantearon la hipótesis de que "la presencia de terreno irregular, mal servido por carreteras, a distancia de los centros de poder estatal, debería favorecer la insurgencia y la guerra civil" (p. 80). A partir de esta declaración, se puede inferir que los insurgentes nacen y mantienen sus retaguardias en lugares fuera del alcance estatal. Los hallazgos de Kalyvas (2006) siguen la misma dirección: "las montañas y el terreno accidentado son generalmente fortalezas insurgentes. La ubicación de los insurgentes se predice mejor mediante variables como el terreno y la distancia desde las bases militares provinciales" (p. 132). La relación entre inaccesibilidad e insurgencia se ha demostrado en otros trabajos (Buhaug \& Rød, 2006; Hendrix, 2011; Tollefsen \& Buhaug, 2015). En conclusión, en los casos en que el estado tiene suficiente capacidad coercitiva, las estrategias contrainsurgentes se centrarán en áreas de fuerte presencia rebelde, que tienden a estar en áreas donde el estado es débil y con terreno inaccesible.

H7: La existencia de retaguardias rebeldes aumenta la probabilidad de disputa territorial.

\section{Disputa territorial en las zonas de fuerte presencia estatal}

Esta explicación se deriva de los casos en que el equilibrio de poder entre el estado y los insurgentes se inclina hacia los insurgentes, y estos buscan obtener el control del estado central. En estos casos, uno esperaría disputas territoriales en puntos estratégicos del poder estatal: las ciudades principales, las vías de comunicación clave y la capital motivarán la disputa territorial. En conclusión, en países y momentos en los que es probable que ganen los rebeldes, la disputa territorial se concentrará en áreas con una fuerte capacidad estatal. Como ejemplo, las guerras ganadas por los insurgentes en El Salvador, 
Libia y Afganistán experimentaron periodos de intensos combates en la capital.

H8: La alta capacidad estatal aumenta la probabilidad de disputa territorial.

La siguiente es la lista de hipótesis que analizaré en la sección empírica.

\section{Mi teoría}

H1: La desigualdad de la tierra está positivamente correlacionada con la capacidad estatal.

H2: La mayor desigualdad de la tierra en contextos de capacidad estatal intermedia está correlacionada con una mayor probabilidad de disputa territorial.

\section{Explicaciones alternativas}

H3: La desigualdad de la tierra por sí sola hace más probable la disputa territorial.

H4: La presencia de cultivos de coca u otras materias primas (commodities), regalías y transferencias está correlacionada con una mayor probabilidad de disputa territorial.

H5: La baja capacidad estatal está correlacionada con una mayor probabilidad de disputa territorial.

H6: El rápido crecimiento económico y de migración están correlacionados con un aumento en la probabilidad de disputas territoriales cuando no existen instituciones estatales fuertes.

H7: La existencia de retaguardias rebeldes aumenta la probabilidad de disputa territorial. 
H8: La alta capacidad estatal aumenta la probabilidad de disputa territorial.

\section{Datos y análisis empírico}

Para determinar cuáles factores influyen en la disputa territorial y cuáles no, utilicé una base de datos de eventos de conflicto compilada por el Centro de Investigación y Educación Popular (CINEP), una ONG que utiliza periódicos, comunicados de prensa e informantes locales para construir una de las bases de datos más completas del conflicto armado colombiano. Como la operacionalización de la variable dependiente requería un proceso manual muy cuidadoso, restringí el análisis estadístico a una muestra aleatoria de 194 municipios. La base de datos del CINEP proporcionó la información para determinar qué municipios estaban en disputa territorial, y otras fuentes proporcionaron los datos para las variables independientes y de control. Para analizar los datos llevé a cabo regresiones logit con errores estándares robustos para autocorrelación y heteroscedasticidad, según lo provisto por el paquete PSCE en R. Además, realicé regresiones logísticas de Firth, que calculan una probabilidad penalizada que se usa con datos que tienen eventos raros. Dado que la disputa territorial es bastante rara, este método proporciona una buena solución para las regresiones logit. Usé el paquete Logistf en $\mathrm{R}$ para calcular estos resultados.

En tanto las dinámicas de los actores armados no se circunscriben a los límites municipales, el uso de los municipios como unidad de análisis no es ideal para hacer este tipo de ejercicios empíricos. Idealmente podríamos dividir el territorio en celdas y calcular las variables de interés promedio para cada una de ellas. En Colombia, no obstante, la mayor parte de las variables se pueden estimar a nivel municipal y no existen mayores desagregaciones. Esta limitación empírica limita la capacidad del trabajo de hacer la mejor estimación posible, por lo que siempre se sugiere el carácter correlacional y no causal de los hallazgos. 


\section{Operacionalización de la disputa territorial}

La disputa territorial se ha definido como una situación que cumple dos condiciones necesarias y conjuntamente suficientes. Primero, un actor armado retador debe intentar obtener el control del territorio X, que es controlado por el actor armado desafiado. Segundo, el actor armado desafiado intenta mantener el control territorial del territorio $\mathrm{X}$.

En general, hay tres estrategias que los actores armados usan cuando intentan obtener y mantener el control. Primero, se involucran en hostilidades (es decir, combates, emboscadas y otras acciones militares); segundo, victimizan a civiles, y tercero, hacen ambas cosas. Utilizando el conjunto de datos del CINEP, presté atención a las siguientes dinámicas de guerra. En las hostilidades, miré combates, emboscadas, bombardeos, ataques a objetivos militares, incursiones y sabotajes. En la victimización civil, miré masacres, homicidios, desapariciones forzadas, desplazamientos colectivos forzados, ataques indiscriminados y saqueos.

Es difícil establecer una fórmula de agregación única o un punto de referencia de disputa territorial. ¿Cuántos combates u homicidios indican que un territorio está siendo disputado? Para aumentar la robustez de mis hallazgos, utilicé dos especificaciones diferentes de mi variable dependiente. Ambas cumplen con las dos condiciones necesarias de mi concepto, pero difieren en si las hostilidades y las estrategias de victimización civil pueden combinarse y la cantidad de eventos que son necesarios para obtener afirmativo (1) en disputa territorial. Las dos especificaciones de la variable dependiente (VD) están etiquetadas como disputa territorial flexible y disputa territorial basada en hostilidades.

\section{Disputa territorial flexible}

En la primera especificación de mi vD, asigno puntos a cada tipo de repertorio violento. Por ejemplo, considero que la mayoría de los eventos de hostilidades valen 3 puntos, mientras que una masacre de 5 o más víctimas, vale 5 puntos. Aunque este sistema de asignación 


\section{I Silvia Otero Bahamón}

de puntos es necesariamente arbitrario, busca reflejar el impacto diferencial de cada tipo de acto en la lucha por el control territorial. Una masacre o un desplazamiento forzado colectivo es necesariamente más efectivo en la lucha por el control que el saqueo o un solo evento de desaparición forzada. Las definiciones de estos repertorios y las reglas de codificación se pueden encontrar en el Apéndice 1.

Considero los puntos y el número de eventos realizados por cada actor armado en cada año/municipio. Si al menos 2 lados opuestos suman cada uno 10 puntos en al menos 3 eventos, codificaré 1 en disputa territorial. Por ejemplo, una localidad obtendría 1 en disputa territorial flexible si los militares bombardean, los paramilitares matan a 7 civiles y alguna guerrilla realiza cuatro ataques a objetivos militares.

\section{Disputa territorial basada en hostilidades}

El propósito de esta especificación de disputa territorial es obtener matices: algunas explicaciones alternativas pueden ser relevantes para la disputa territorial impulsada por las hostilidades, pero no para la disputa territorial en la que los civiles son el objetivo principal.

Una localidad obtiene un puntaje de 1 en disputa territorial basada en hostilidades cuando al menos dos bandos en confrontación llevan a cabo al menos 3 acciones de hostilidades en un periodo de un año.

\section{Operacionalización de la desigualdad de la tierra}

Para la desigualdad de la tierra, usé los datos rurales de Gini para 1996 y 1985 y creé la variable ginidif, que resta el valor de 1996 al valor de 1985. Si es positiva, la variable muestra que la desigualdad en un municipio en particular ha aumentado en ese periodo de 10 años. Si es negativa, la variable muestra que se ha producido un proceso de igualación de tierras. Los datos fueron recopilados por el IGAC y preparados por el Cerac ${ }^{3}$. El periodo 1985-1996 es conveniente porque mide la producción de desigualdad de la tierra años antes del periodo en que se observará la disputa territorial.

3 Se incluye como parte del apéndice en línea de Vásquez et al. (2011). 


\section{Operacionalización de la capacidad estatal}

Soifer y vom Hau (2008) argumentan que los conceptos relacionados con la fortaleza y la debilidad estatal han sido tratados con muy poco rigor en la literatura académica. Términos similares tales como el alcance estatal, el poder, la presencia o la capacidad generalmente se usan indistintamente. Con el fin de traer un cierto orden conceptual, los autores abogan por el uso del concepto de Michael Mann del poder infraestructural estatal, que es la "capacidad institucional para ejercer control e implementar las decisiones de política dentro del territorio que dice gobernar" (Soifer \& vom Hau, 2008, p. 220). Con este concepto, los académicos pueden analizar la variación espacial en la capacidad estatal para ejercer control y regular la sociedad. Estos autores sostienen que dicha capacidad se refiere a tres cosas: el grado en que el estado está presente en la vida cotidiana de las personas, el grado en que el estado penetra el territorio y el grado en que el estado puede gravar a la población.

En este trabajo pruebo primero si el aumento de la desigualdad de la tierra tiene un impacto en la capacidad estatal y, en segundo lugar, si la capacidad estatal intermedia tiene una correlación con la disputa territorial. Para los dos modelos incluyo variables de al menos dos de las tres dimensiones de la capacidad estatal.

Para medir el grado en que el estado está presente en la vida cotidiana de las personas, utilicé el porcentaje de personas en un municipio con acceso a alcantarillado y tasa de mortalidad infantil. En Colombia, las autoridades locales deben proporcionar alcantarillado y, por lo tanto, la cobertura de alcantarillado es un indicador del grado en que el estado local está presente en la vida de las personas. Los datos están disponibles para el año 2000 y son proporcionados por el Departamento Nacional de Planificación y compilados por el CERAC. La tasa de mortalidad infantil refleja la existencia de infraestructura de salud y programas adecuados de promoción y prevención, que al final muestran la capacidad estatal para influir en las tradiciones locales de cuidado infantil. Los datos a nivel municipal solo están disponibles a partir de 2005. 


\section{4 / Silvia Otero Bahamón}

El grado en que el estado penetra el territorio se medió con la densidad de carreteras pavimentadas. Este indicador se ha utilizado en análisis importantes de la formación de estados en otras regiones (ver Herbst 2000). Los datos disponibles son de 1990 y provienen de un censo de carreteras único realizado por el gobierno de César Gaviria. Para entonces, la construcción de carreteras era una función del estado central. Este indicador medirá la capacidad del estado central para penetrar en el territorio. El indicador de densidad de carreteras pavimentadas es particularmente apropiado porque se midió en 1990, en un momento en que el conflicto aún tenía una intensidad baja. Durante aquella década, los diferentes gobiernos no prestaron mucha atención a las carreteras municipales, debido a las reformas de descentralización y la liquidación de Caminos Vecinales. Dichas reformas de descentralización dieron a los municipios la responsabilidad de construir carreteras de tercer nivel, pero no los fondos para hacerlo, por lo cual la red permaneció estancada. Además, la crisis fiscal de fines de la década de 1990 significó recortes en todos los ámbitos, especialmente en la construcción de infraestructura. El conflicto, por lo tanto, no había influido mucho en la construcción de infraestructura hasta la década de 1990 y factores exógenos hicieron que la infraestructura se estancara durante gran parte de ella.

Por último, el grado en que el estado puede gravar a la población se mide a través de la tributación per cápita, el impuesto predial per cápita o el porcentaje de los ingresos generados localmente sobre los ingresos totales. Estas variables fiscales están incluidas en el panel municipal hecho por el Centro de Estudios sobre Desarrollo Económico (CEDE) de la Universidad de los Andes. Las tres medidas evidencian la cantidad de impuestos recaudados por las autoridades estatales locales.

Para los primeros modelos de desigualdad de la tierra como predictor de la capacidad estatal, utilicé la tasa de mortalidad infantil (2005), la cobertura de alcantarillado (2000) y los impuestos per cápita (1996). La idea fue evaluar el impacto de una década de concentración de la tierra (1985-1996) en la capacidad estatal. Dado el marco temporal de la variable independiente, no incluí la densidad de carreteras como 
un proxy de variable dependiente, ya que estos datos solo están disponibles para 1990.

Para el segundo grupo de modelos de capacidad estatal como predictores de disputas territoriales, utilicé la cobertura de alcantarillado (2000), el impuesto predial per cápita (2000-2004) y la densidad de carreteras pavimentadas (1990). Como una de mis hipótesis predice que un nivel intermedio de capacidad estatal está correlacionado con disputa territorial, modelé una relación parabólica entre la capacidad estatal y la disputa territorial. Es decir que niveles bajos de capacidad estatal están correlacionados con niveles bajos de disputa territorial; niveles intermedios de capacidad estatal con niveles altos de disputa, y niveles altos de capacidad con niveles bajos de disputa, siguiendo una U invertida. Para hacerlo, incluí los términos cuadrados de cobertura de alcantarillado, densidad de carreteras e impuestos.

\section{Controles}

Probar H1: desigualdad de la tierra (IV); capacidad estatal (VD)

Para probar H1 o evaluar la correlación entre la desigualdad de la tierra y la capacidad estatal debimos controlar por la capacidad inicial y otras variables que pueden influir tanto en la capacidad estatal como en la desigualdad de la tierra. Como controles, agregué el impuesto per cápita para 1984 (un año antes de la primera medición de Gini), el área, la población y el número total de acciones ofensivas de todos los actores armados entre 1993 y 1996. Para esta última variable no teníamos información para años antes. La lógica detrás de incluir este control es tener en cuenta el hecho de que las estrategias ofensivas de los actores armados pueden determinar un aumento en la tierra con la medición de Gini y la capacidad estatal.

Probar H2: capacidad estatal (VI); Modelos de disputas territoriales (VD)

Para probar H4 o la relación entre los recursos naturales, las transferencias o las materias primas en la probabilidad de disputa territorial, 


\section{6 / Silvia Otero Bahamón}

incluí el número de hectáreas de cultivos de coca, ${ }^{4}$ regalías $^{5}$ y transferencias. ${ }^{6}$

Para probar H6, utilicé una medida del crecimiento de la población como indicador de la migración y el desarrollo económico, y tomé la diferencia entre la población municipal de 1997 y 1985. Ambas estadísticas son producidas por el Departamento Administrativo Nacional de Estadística (DANE) y compiladas por la Fundación Social. Para probar completamente la hipótesis huntingtoniana de la disfunción social: el rápido crecimiento económico y de población conduce a una disputa territorial cuando las instituciones estatales están ausentes, interactúe el crecimiento de la población con mediciones tributarias de la capacidad estatal. Para evitar la correlación con otras medidas de capacidad estatal, utilicé el porcentaje del ingreso local proveniente de impuestos.

Para probar $\mathrm{H} 7$ o si las retaguardias guerrilleras aumentan la probabilidad de disputa utilicé dos proxies de la presencia de guerrillas: baja capacidad estatal y terreno montañoso. Se ha encontrado que el terreno montañoso es favorable a las actividades rebeldes en los estudios transversales (Fearon \& Laitin 2003) y colombianos (Gonzalez et al., 2003).

Las medidas de capacidad estatal también sirven para probar $\mathrm{H} 5$ y $\mathrm{H} 8$, que enfatizan que la baja (alta) capacidad estatal en los sitios de mayor centralidad aumenta la probabilidad de disputas territoriales. También incluí variables de control de área y población del panel municipal del CEDE. Uno esperaría que los municipios más grandes sean más difíciles de controlar, lo que haría más probable la disputa.

También controlé por la existencia de actividad temprana del grupo insurgente. Intenté controlar a partir del argumento presentado por Saffon y Sánchez (2017) que establece que los primeros despojos de tierras conducen a nuevos despojos mediante la creación de grupos

\footnotetext{
$4 \quad$ Proviene de la base de datos de SIMCI.

5 Datos del panel municipal del CEDE.

6 Datos del panel municipal del CEDE.
} 
rebeldes. Quise controlar la actividad temprana de la guerrilla para descartar una relación espuria en la que la actividad temprana del grupo rebelde hubiera conducido tanto al despojo de tierras y la desigualdad de la tierra, como a la disputa territorial. Al controlar la actividad temprana de la guerrilla, el artículo enfatiza que la creciente desigualdad convierte a un lugar en blanco de disputas territoriales, incluso controlando la posible intervención de grupos armados en el periodo de producción de desigualdad. Para hacerlo, creé la variable ofensivasAA93, construida a partir del panel de conflicto y violencia del CEDE que agrega el número de ofensivas de todos los actores armados en 1993, el primer año del panel.

\section{Análisis estadístico}

\section{Desigualdad de la tierra y capacidad estatal}

Ahora, como sostuve en la primera parte de este artículo, sugiero que el proceso de concentración de la tierra rural va de la mano con el proceso de formación del estado. Para demostrar este punto, realicé una regresión de cuadrados ordinarios tomando tres manifestaciones de la capacidad estatal a nivel municipal como variables dependientes: impuesto per cápita, cobertura de alcantarillado y tasa de mortalidad infantil. El primero captura la capacidad estatal por su nivel de tributación, que incluye los impuestos a la propiedad y los impuestos al comercio. La segunda variable evalúa el desempeño del estado local en la provisión de un bien público. La tercera, la tasa de mortalidad infantil, es una representación de cómo la capacidad estatal produce bienestar entre los individuos. Mayores capacidades estatales implican una mejor infraestructura de salud e información sobre las condiciones individuales. El impuesto local per cápita se toma para 1996, la tasa de mortalidad infantil para el 2005 (primer año disponible) y la cobertura de alcantarillado para el 2000.

Como variable independiente usé la diferencia en los valores de Gini de la tierra municipal entre 1996 y 1985. Los resultados se presentan en la tabla 1. 
Tabla 1. Determinantes de la capacidad estatal en Colombia

\begin{tabular}{|c|c|c|c|}
\hline Variable dependiente & $\begin{array}{l}\text { Impuesto per } \\
\text { cápita }\end{array}$ & $\begin{array}{c}\text { Tasa de } \\
\text { mortalidad } \\
\text { infantil }\end{array}$ & $\begin{array}{l}\text { Cobertura de } \\
\text { alcantarillado }\end{array}$ \\
\hline Año de la variable dependiente & 1996 & 2005 & 2000 \\
\hline Modelo & 1 & 2 & 3 \\
\hline Intercepto & $\begin{array}{c}-0,0002 \\
(0,00106)\end{array}$ & $\begin{array}{c}3,117 \\
\left(0,0128^{* * *}\right)\end{array}$ & $\begin{array}{c}0,0963 \\
(0,00924 * * *)\end{array}$ \\
\hline Diferencia de Gini 96-86 & $\begin{array}{c}0,00003 \\
(0,00001 *)\end{array}$ & $\begin{array}{c}-0,00339 \\
\left(0,00134^{*}\right)\end{array}$ & $\begin{array}{c}0,0033 \\
(0,001 * *)\end{array}$ \\
\hline Impuesto local per cápita en 1984 & $\begin{array}{c}7,167 \\
\left(0,257^{* * *}\right) \\
\end{array}$ & $\begin{array}{c}-2,243,2 \\
\left(29,81^{* * *}\right)\end{array}$ & $\begin{array}{c}215,3 \\
\left(21,51^{* * *}\right)\end{array}$ \\
\hline Población 1993 & $\begin{array}{c}-0,0000 \\
\left(0,0000^{* * *}\right) \\
\end{array}$ & $\begin{array}{c}-0,000 \\
(-0,000 * * *) \\
\end{array}$ & $\begin{array}{c}-0,0000 \\
\left(0,0000^{* * *}\right) \\
\end{array}$ \\
\hline Área & $\begin{array}{c}0,0000 \\
(0,0000) \\
\end{array}$ & $\begin{array}{c}-0,000 \\
(0,000 * * *) \\
\end{array}$ & $\begin{array}{c}-0,0000 \\
\left(0,0000^{* * *}\right) \\
\end{array}$ \\
\hline Acciones ofensivas de todos los AA & $\begin{array}{c}0,00001 \\
(0,00001)\end{array}$ & $\begin{array}{l}-0,00138 \\
(0,00179)\end{array}$ & $\begin{array}{c}-0,0006 \\
(0,00129)\end{array}$ \\
\hline Controles departamentales & Yes & No & No \\
\hline $\mathrm{R}$ cuadro ajustado & 0,5454 & 0,218 & 0,3 \\
\hline Observaciones & 703 & 703 & 703 \\
\hline
\end{tabular}

Errores estándares entre paréntesis

$* \mathrm{p}<0,05, * * \mathrm{p}<0,01, * * * \mathrm{p}<0,001$

Fuente: CEDE (Uniandes); IGAC (compilados por Cerac).

Transformación de variables para mejores residuos: Cuadrado de Impuesto per cápita y cobertura alcantarillado, Log de TMI.

Según los resultados, existe una relación positiva y significativa entre una creciente desigualdad de la tierra y la capacidad estatal, incluso controlando la capacidad estatal anterior y la actividad del actor armado. Una mayor desigualdad en la distribución de la tierra se correlaciona con una mayor cobertura de alcantarillado, un mayor impuesto per cápita y una menor tasa de mortalidad infantil (signo negativo). Estas regresiones respaldan las hipótesis de los historiadores y sociólogos que han estudiado durante décadas el proceso de formación del estado colombiano (ver González, 2010; 2014; Pécaut, 2001). 
En resumen, la producción de desigualdad rural fue de la mano de los aumentos en la capacidad estatal y, como argumentaré más adelante, un nivel intermedio de la capacidad estatal aumenta la probabilidad de disputa territorial.

\section{Capacidad estatal y disputa territorial}

Estadísticas descriptivas

Un total de 68 observaciones por año/municipio se disputan territorialmente de acuerdo con al menos una especificación de disputa territorial. Estas observaciones se distribuyen entre 33 municipios en 19 departamentos. Esto significa que el 7,9\% de las observaciones y el $21 \%$ de los municipios se disputan territorialmente al menos un año (Apéndice 2).

Los departamentos con más casos de disputas territoriales por año/municipio son Antioquia (10), Arauca (9) y Cauca (6). Los departamentos con muy pocos casos de disputa territorial son Cundinamarca, Bolívar, Casanare, Magdalena, Guajira, Tolima, Santander, Nariño, Guaviare y Caquetá.

De acuerdo con la primera especificación de la VD, disputa territorial flexible, encontramos 50 observaciones por año/municipio. Según la segunda especificación, 67 por años/municipio se codifican como disputa territorial basada en hostilidades.

La distribución de municipios y la lista de municipios disputados territorialmente se presentan en la figura 2. 
Figura 2. Disputa territorial en los departamentos colombianos

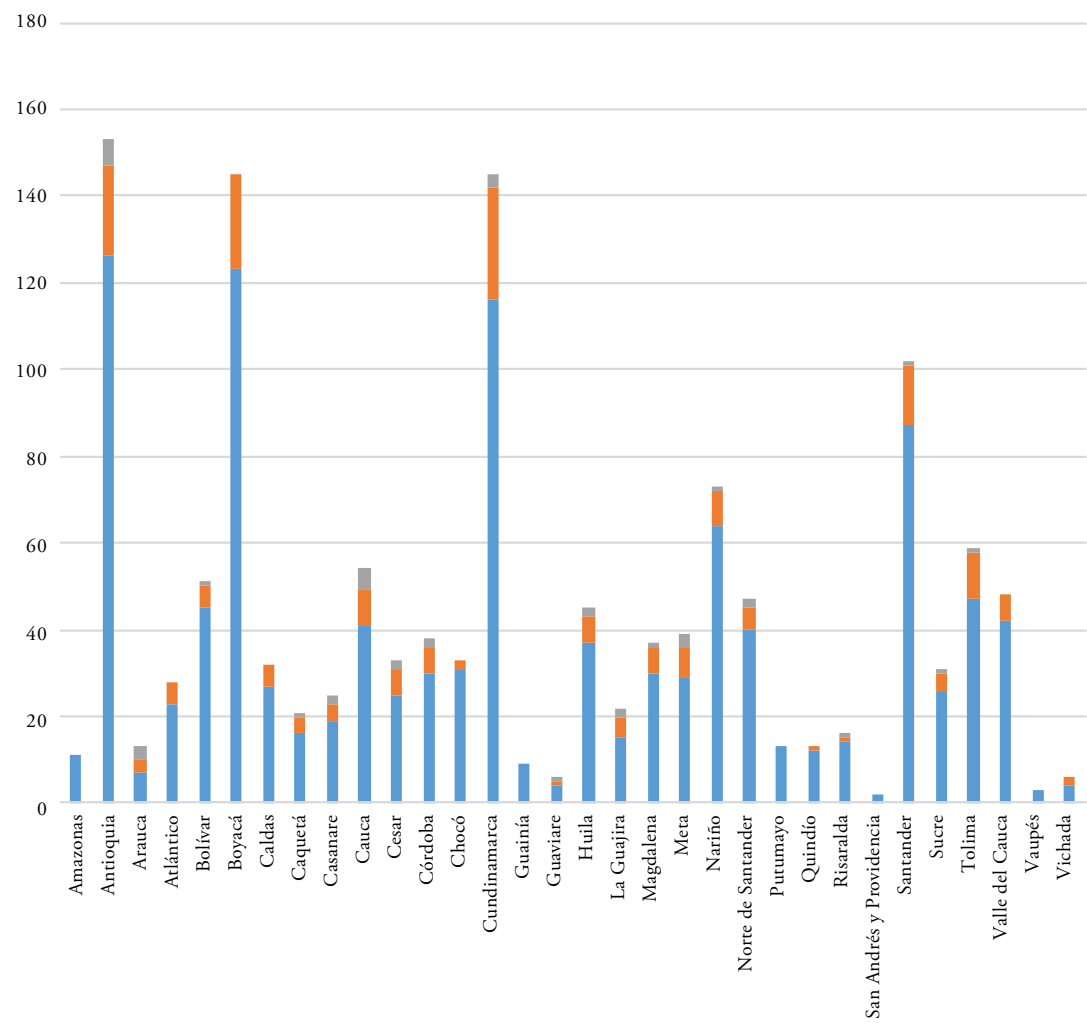

- Total de municipios Municipios en la muestra Municipios con disputa territorial

Fuente: elaboración propia.

\section{Resultados}

La tabla 2 muestra los resultados de doce modelos diferentes. Para recordar al lector, evalué mis hipótesis con tres manifestaciones de la capacidad estatal: densidad de carreteras pavimentadas, impuesto sobre la tierra per cápita y cobertura de alcantarillado. Para cada proxy de capacidad estatal, utilicé dos especificaciones de la variable dependiente (disputa territorial flexible y disputa territorial basada en hostilidades) y calculé dos especificaciones de modelo diferentes: una regresión logit con errores estándar corregidos por panel para autocorrelación y heterocedasticidad, y regresión logística de Firth, que calcula una probabilidad penalizada en situaciones de eventos 
raros. Como afirma Wang (2014), "la atracción de este método es que proporciona una reducción de sesgo para muestras pequeñas, así como también proporciona estimaciones finitas y consistentes incluso en caso de separación” (p. 1).

En otras palabras, en los modelos 1 a 4 usé la densidad de carreteras pavimentadas como principales variables independientes, en los modelos 5 a 8, el impuesto a la tierra per cápita y en los modelos 9 a 12, la cobertura de alcantarillado. Para los modelos 1, 3, 5, 7, 9 y 11 utilicé la disputa territorial flexible como variable dependiente y para el resto, la disputa territorial basada en hostilidades. Por último, en los modelos 1, 2, 5, 6, 9 y 10 calculé la regresión logit con errores estándar robustos y en los modelos 3, 4, 7, 8, 10 y 11, la regresión logística de Firth.

Encontré un fuerte apoyo a mi teoría de que existe una correlación entre la desigualdad de la tierra y la capacidad estatal intermedia con la disputa territorial. La versión normal del proxy de capacidad estatal es significativa en 7 de los 12 modelos, y la versión cuadrada es significativa en 6 de 12. Lo más importante, la interacción entre la capacidad estatal y la desigualdad de la tierra es significativa en 8 de los 12 modelos.

El hecho de que los términos normales y cuadrados de estas variables de capacidad estatal sean significativos, así como la interacción entre la desigualdad de la tierra y la capacidad estatal, sugiere la existencia de una relación en forma de $\mathrm{U}$ invertida entre la capacidad estatal y la disputa territorial, y que los efectos de la desigualdad de tierras en la disputa territorial están mediados por la capacidad estatal (tabla 2 y figura 3).

Con respecto a las teorías alternativas, la hipótesis que mira la desigualdad de la tierra por si misma (H3) goza de un apoyo parcial, ya que esta variable es significativa en 4 de los 12 modelos, lo que sugiere que sus efectos sobre la disputa territorial podrían evaluarse mejor cuando interactúan con la capacidad estatal. Ninguno de los proxies de recursos $(\mathrm{H} 4)$ son significativos en la mayoría de los 


\section{I Silvia Otero Bahamón}

modelos. Las hectáreas con coca son significativas en solo dos modelos, y las transferencias y regalías son insignificantes en todos los modelos. La hipótesis de Huntington (H6) de alto crecimiento de la población sin instituciones como motor de disputas territoriales no es significativa en ningún modelo.

El hecho de que el terreno montañoso no sea un predictor de disputa territorial sugiere que esta no ocurre en las zonas de mayor inaccesibilidad, que tienden a albergar los santuarios rebeldes. Del mismo modo, ninguno de los indicadores de la capacidad estatal sugirió una correlación entre la alta capacidad estatal y la disputa territorial. Los resultados sugieren que no hay soporte para las hipótesis 7 y 8 .

Los modelos que utilizan el impuesto local per cápita como proxy de la capacidad estatal brindan apoyo a la $\mathrm{H} 5$ o a que esa baja capacidad aumenta la probabilidad de disputa territorial. En estos modelos, un mayor impuesto a la propiedad per cápita reduce la probabilidad de disputa territorial. Parece entonces que diferentes manifestaciones de la capacidad estatal tienen diferentes impactos en la disputa territorial. Más impuestos impiden que un área sea disputada, pero los niveles intermedios de infraestructura y bienes públicos hacen que la disputa sea más probable. Sin embargo, cuando se ha producido la desigualdad de la tierra, los bajos impuestos per cápita no conducen a disputas territoriales.

Con respecto a los controles, solo el área se volvió significativa, lo que sugiere que los municipios más grandes son propensos a disputas territoriales. Cada año fue significativo en algunos modelos, pero no en otros. En general, en el 2002 aumentaron las posibilidades de disputa territorial entre los municipios. Por último, la actividad del grupo armado temprano no fue un buen predictor de disputas territoriales. 


\begin{tabular}{|c|c|c|c|c|c|c|c|c|c|c|c|c|c|c|c|}
\hline \multirow{4}{*}{ 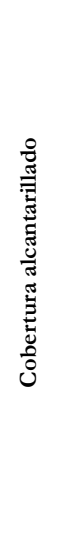 } & 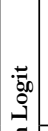 & $\approx$ & 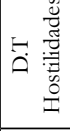 & 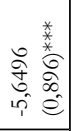 & 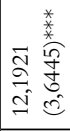 & 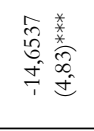 & 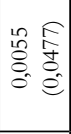 & $\begin{array}{cc}\vec{\sigma} & \widehat{\sigma} \\
\vec{\sigma} & \hat{\sigma} \\
0 & 0 \\
0 & \hat{e}\end{array}$ & 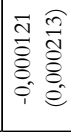 & 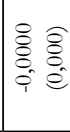 & 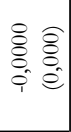 & 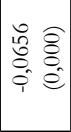 & 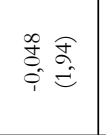 & 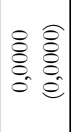 & 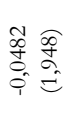 \\
\hline & 新 & $=$ & 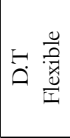 & 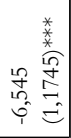 & 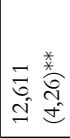 & $\begin{array}{l}m^{\infty} \\
\overbrace{}^{2} \\
\overbrace{}^{2}\end{array}$ & 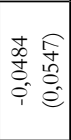 & 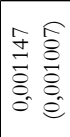 & 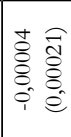 & 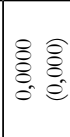 & 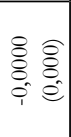 & 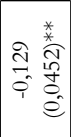 & 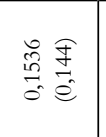 & 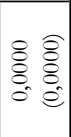 & 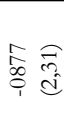 \\
\hline & 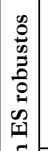 & $\circ$ & 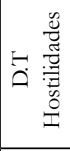 & 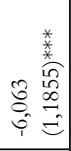 & 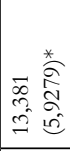 & 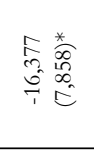 & 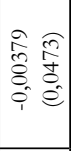 & 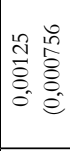 & 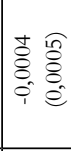 & 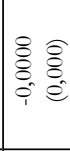 & 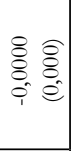 & 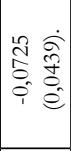 & 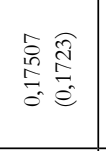 & 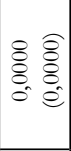 & 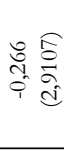 \\
\hline & 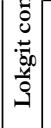 & $a$ & 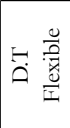 & 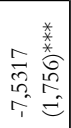 & 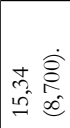 & 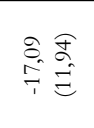 & 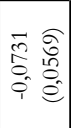 & 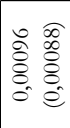 & 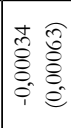 & 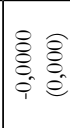 & 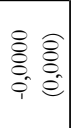 & 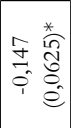 & $\vec{i} \frac{\widehat{a}}{\hat{i}}$ & 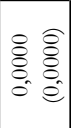 & 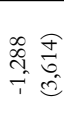 \\
\hline \multirow{4}{*}{ 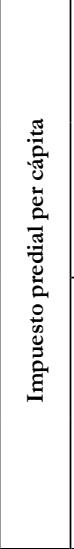 } & 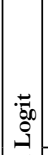 & $\infty$ & 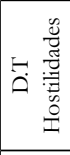 & 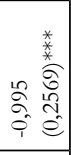 & 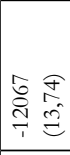 & 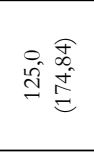 & 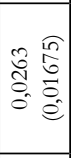 & 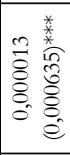 & 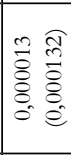 & 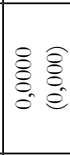 & 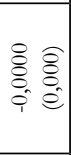 & & 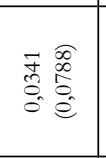 & 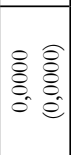 & 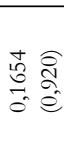 \\
\hline & 全 & $r$ & 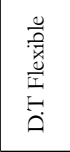 & 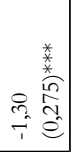 & \begin{tabular}{ll}
$o$ & $\hat{b}$ \\
$o$ & 0 \\
\hdashline & $\mathbb{E}$
\end{tabular} & 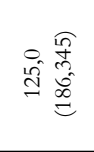 & 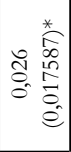 & 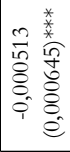 & 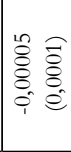 & 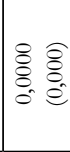 & 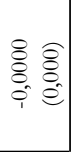 & & 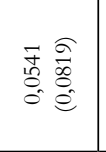 & 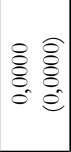 & 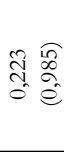 \\
\hline & \begin{tabular}{|c|} 
\\
0 \\
0 \\
0 \\
0 \\
0 \\
0 \\
0 \\
0 \\
0 \\
1 \\
$\mid 10$ \\
\end{tabular} & 6 & 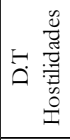 & 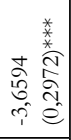 & 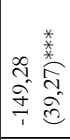 & 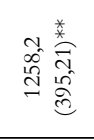 & 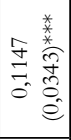 & 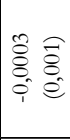 & 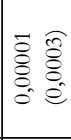 & 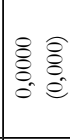 & 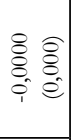 & & 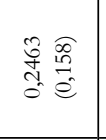 & $\begin{array}{ll}\delta & \vdots \\
\vdots & \vdots \\
0 & \vdots \\
0^{\prime} & \hat{2}\end{array} \mid$ & 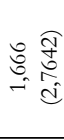 \\
\hline & 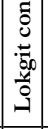 & in & 볼 & 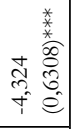 & 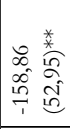 & 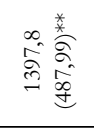 & 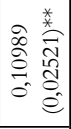 & 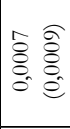 & 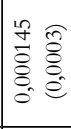 & 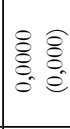 & 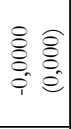 & & 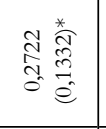 & 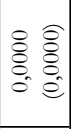 & 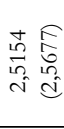 \\
\hline \multirow{4}{*}{ 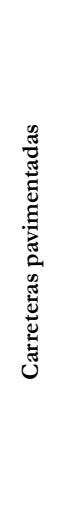 } & 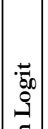 & + & 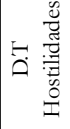 & 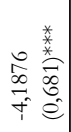 & $\begin{array}{ll}0 & 0 \\
n & 0 \\
m & 0\end{array}$ & 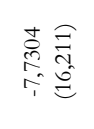 & 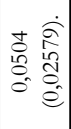 & $\left|\begin{array}{ll}0 & \widehat{\hat{o}} \\
0 & 0 \\
0 & 0 \\
0 & \hat{e}\end{array}\right|$ & 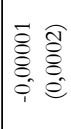 & 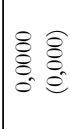 & 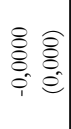 & 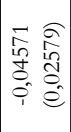 & 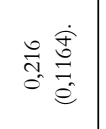 & 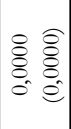 & 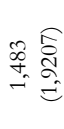 \\
\hline & 表 & $m$ & 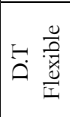 & 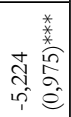 & 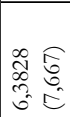 & 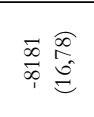 & 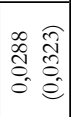 & 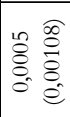 & 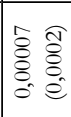 & 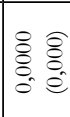 & 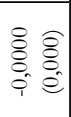 & 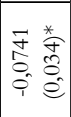 & 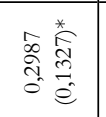 & 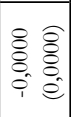 & 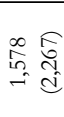 \\
\hline & \begin{tabular}{|c|}
0 \\
0 \\
0 \\
0 \\
0 \\
0 \\
0 \\
0 \\
0 \\
$\mid$
\end{tabular} & N & 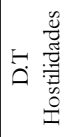 & 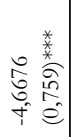 & 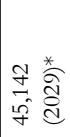 & 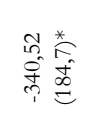 & 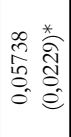 & $\mid \begin{array}{ll}\hat{o} & \widehat{\bar{g}} \\
0 \\
0 & \hat{e}\end{array}$ & 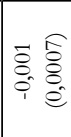 & 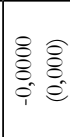 & 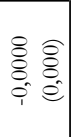 & 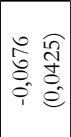 & 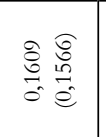 & $\begin{array}{ll}\delta & \vdots \\
\vdots & \vdots \\
0 & \vdots \\
0^{\prime} & \hat{\varepsilon}\end{array} \mid$ & 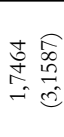 \\
\hline & 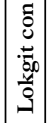 & - & H. & 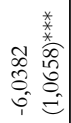 & 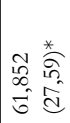 & 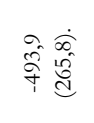 & 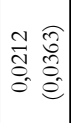 & $\mid \begin{array}{ll}\infty & \widehat{\delta} \\
0 & \overline{8} \\
0 & \hat{e}\end{array}$ & $\mid$\begin{tabular}{cc}
0 & \multicolumn{1}{c}{} \\
0 & 0 \\
0 & 0 \\
0 & 0 \\
0 & 0 \\
1 & 0 \\
1
\end{tabular} & 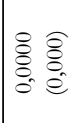 & 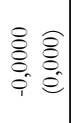 & 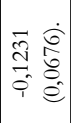 & $\begin{array}{l}\infty \\
\infty \\
\infty \\
0 \\
0 \\
0 \\
0\end{array}$ & 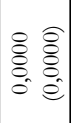 & 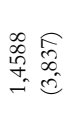 \\
\hline 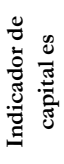 & & & $\frac{0}{\frac{0}{\pi}}$ & 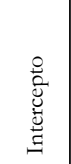 & 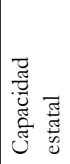 & 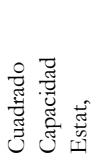 & 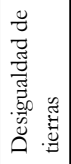 & 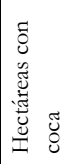 & 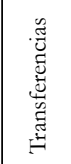 & 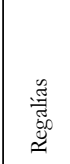 & 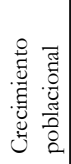 & 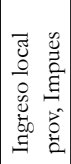 & 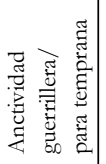 & 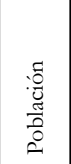 & 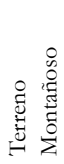 \\
\hline
\end{tabular}




\begin{tabular}{|c|c|c|c|c|c|c|c|c|c|c|c|c|c|c|c|}
\hline \multirow{4}{*}{ 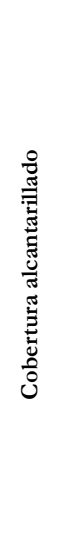 } & 范 & $\approx$ & 旨: & 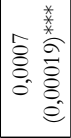 & & 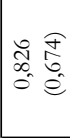 & 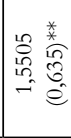 & 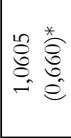 & $\begin{array}{lll}0 & \widehat{尺} \\
\infty & 0 \\
0 & 0 & 0 \\
0 & 0\end{array}$ & & 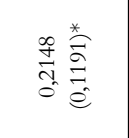 & 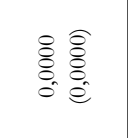 & & స్ర & \\
\hline & 全 & $=$ & 旨: & 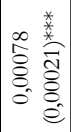 & & 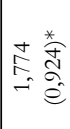 & 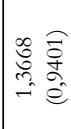 & 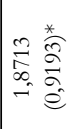 & 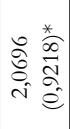 & & 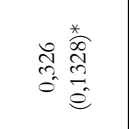 & 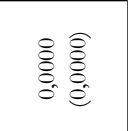 & & $\stackrel{\mathbb{V}}{\mathbb{S}}$ & \\
\hline & \begin{tabular}{c|}
0 \\
0 \\
0 \\
0 \\
0 \\
0 \\
0 \\
0 \\
1
\end{tabular} & 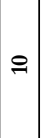 & 旨: & 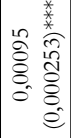 & & 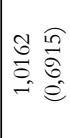 & 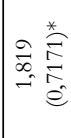 & 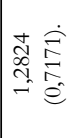 & 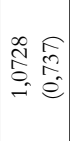 & & 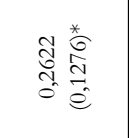 & 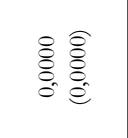 & & స్ర & 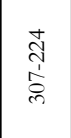 \\
\hline & 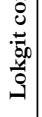 & $a$ & $\stackrel{\frac{0}{0}}{\stackrel{0}{0}}$ & 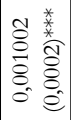 & & 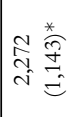 & 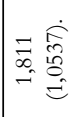 & 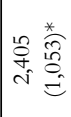 & 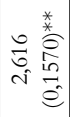 & & 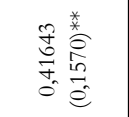 & 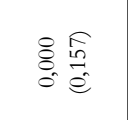 & & $\stackrel{\mathbb{V}}{ }$ & $\begin{array}{l}\text { in } \\
\text { o } \\
\text { ते }\end{array}$ \\
\hline \multirow{4}{*}{ 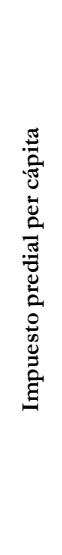 } & 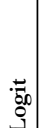 & $\infty$ & 占: & 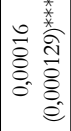 & & 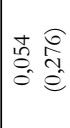 & 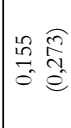 & 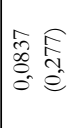 & 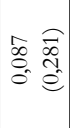 & & 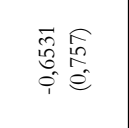 & & 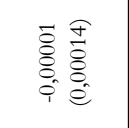 & 茴 & \\
\hline & 章 & $r$ & 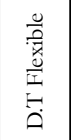 & 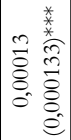 & & 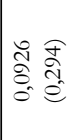 & 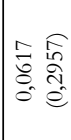 & 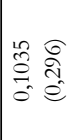 & 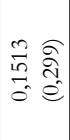 & & 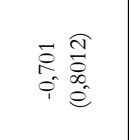 & & 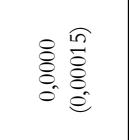 & 獣 & \\
\hline & \begin{tabular}{c|}
0 \\
0 \\
0 \\
0 \\
0 \\
0 \\
0 \\
0 \\
1
\end{tabular} & ๑ & 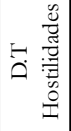 & 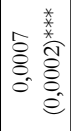 & & 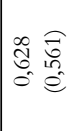 & 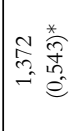 & 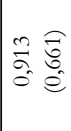 & 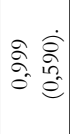 & & 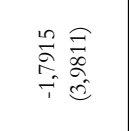 & & 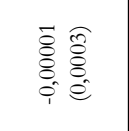 & 獣 & 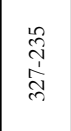 \\
\hline & 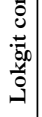 & in & $\stackrel{\frac{0}{0}}{\circ}$ & 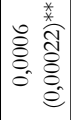 & & 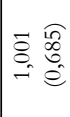 & 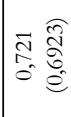 & $\begin{array}{ll}\vec{T} & \widehat{A} \\
0 & \mathbb{N} \\
- & \hat{e}\end{array}$ & 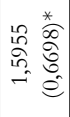 & & 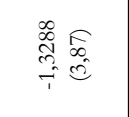 & & 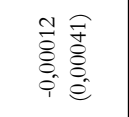 & 跔 & 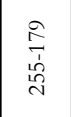 \\
\hline \multirow{4}{*}{ 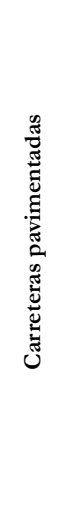 } & 范 & + & 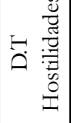 & 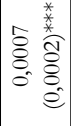 & & 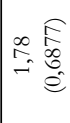 & 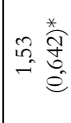 & 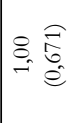 & 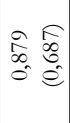 & & 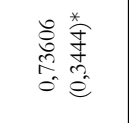 & 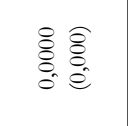 & & đ্ত & \\
\hline & 童 & $m$ & 旨 & 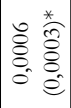 & & 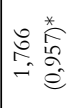 & $\begin{array}{l}\hat{?} \\
\stackrel{\hat{\sigma}}{\hat{S}}\end{array}$ & $\begin{array}{l}\stackrel{*}{\vec{n}} \\
\stackrel{*}{\hat{n}}\end{array}$ & 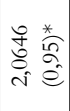 & & 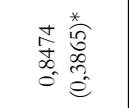 & 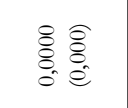 & & స్ర & \\
\hline & $\begin{array}{c}0 \\
0 \\
0 \\
0 \\
0 \\
0 \\
4 \\
0 \\
\text { II }\end{array}$ & $\sim$ & 占: & 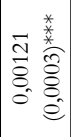 & & $\begin{array}{cc}\hat{\sigma} & \stackrel{f}{N} \\
\hat{\sigma} & \hat{e}\end{array}$ & 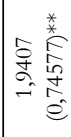 & 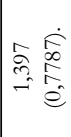 & \begin{tabular}{ll}
$\infty$ & $\widehat{\hat{O}}$ \\
\multirow{2}{*}{} & $\hat{e}$
\end{tabular} & & 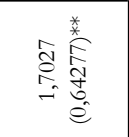 & 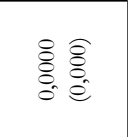 & & तु & 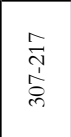 \\
\hline & 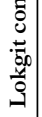 & - & 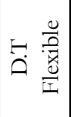 & 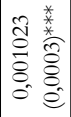 & & 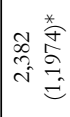 & 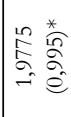 & 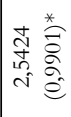 & 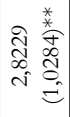 & & 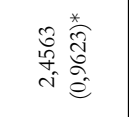 & $\begin{array}{l}\stackrel{\dot{\sigma}}{8} \\
0_{0}^{\circ}\end{array}$ & & $\stackrel{\mathbb{S}}{\mathbb{S}}$ & $\begin{array}{l}\stackrel{0}{n} \\
\text { à } \\
\text { ปn }\end{array}$ \\
\hline 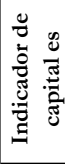 & & & $\frac{0}{\frac{0}{\pi}}$ & $\frac{\tilde{H}}{\frac{\mathrm{g}}{\tilde{J}}}$ & 实 & ¿ & §ิ & ڤ్రి & 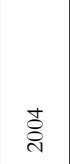 & 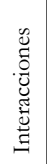 & 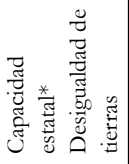 & 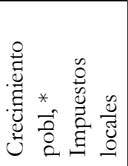 & 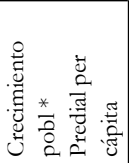 & 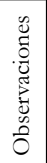 & 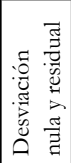 \\
\hline
\end{tabular}


Figura 3. Probabilidad de disputa territorial para distintos valores de densidad de carreteras pavimentadas

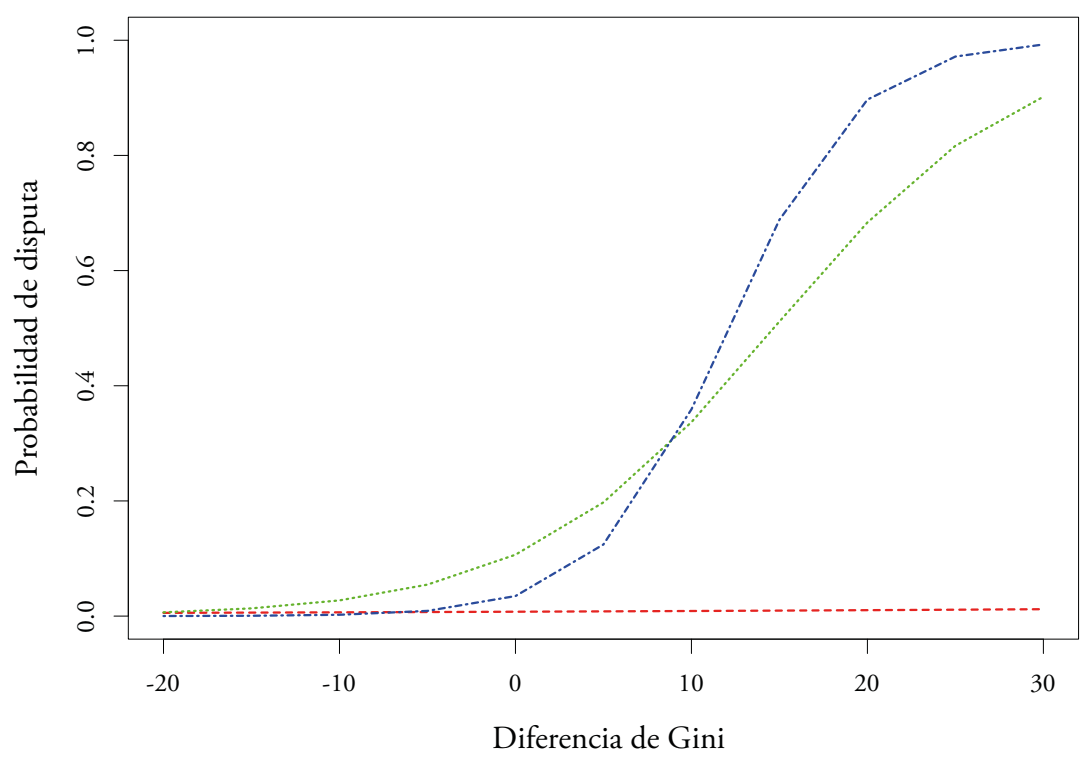

Nota: Línea Roja: 1 desviación estándar por debajo de la densidad promedio de carreteras pavimentadas. Línea verde: densidad promedio de carreteras pavimentadas. Línea azul: 1 desviación estándar por arriba de la densidad promedio de carreteras pavimentadas.

Fuente: elaboración propia.

La figura 3 muestra el efecto de la desigualdad de la tierra en la probabilidad de disputa territorial para diferentes niveles de la capacidad estatal. La línea roja calcula las probabilidades predichas de disputa territorial para baja densidad de carreteras pavimentadas, la línea verde muestra la probabilidad para densidad promedio de carreteras pavimentadas y la línea azul muestra las probabilidades predichas de disputa territorial para alta densidad de carreteras pavimentadas. Como podemos observar, cuando la densidad de carreteras pavimentadas es baja, incluso los grandes incrementos en la desigualdad de la tierra no aumentan la probabilidad de disputa territorial. Sin embargo, cuando la densidad de carreteras pavimentadas está en sus valores medios o altos, el aumento de la desigualdad de la tierra está correlacionado con una mayor probabilidad de disputa territorial. Estos resultados apoyan la H2: la desigualdad de la tierra estimula la disputa territorial solo cuando hay suficiente capacidad estatal. La desigualdad de la tierra por sí sola no produce disputa territorial. Si dicha desigualdad se 
traduce en agravios, estos requieren los incentivos y oportunidades que permiten una capacidad estatal intermedia.

Figura 4. Probabilidad de disputa territorial para distintos indicadores de capacidad estatal
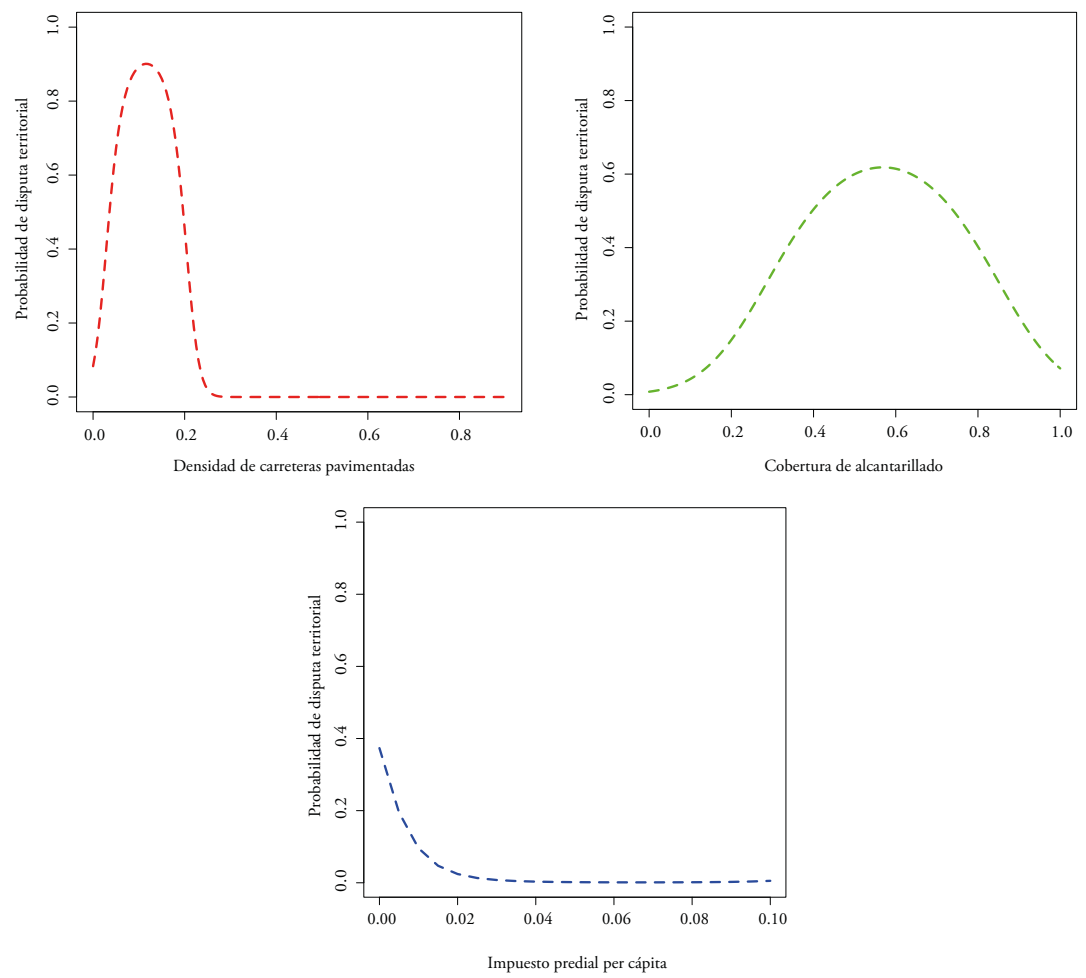

Fuente: elaboración propia.

La figura 4 muestra las probabilidades pronosticadas de disputa territorial para diferentes valores de capacidad estatal. Como podemos observar, para los modelos de densidad de carreteras pavimentadas y de alcantarillado existe una relación en forma de $\mathrm{U}$ invertida entre la capacidad estatal y la disputa territorial. La disputa territorial es poco probable en la capacidad estatal baja o alta, pero mucho más probable en el medio. La disputa territorial es probable con una densidad de carreteras pavimentadas de 0,1 y $60 \%$ de cobertura de alcantarillado. El modelo de impuesto predial per cápita muestra una excepción. En esta especificación, la capacidad del estado local se 
correlaciona negativamente con la disputa territorial. Es decir, a más impuesto, menos disputa.

La recurrencia de disputas territoriales en áreas con capacidad estatal intermedia — especialmente en términos de carreteras y bienes públicos- da peso a la hipótesis de que estas áreas brindan oportunidades e incentivos para obtener y mantener el control, lo que aumenta la probabilidad de disputa territorial.

\section{Conclusiones}

En este artículo me concentré en un fenómeno de guerra civil que aún no se ha abordado en la literatura sobre el tema. Creé el concepto de disputa territorial con el objetivo de capturar la interacción entre los actores armados en un territorio. Además, proporcioné una teoría convincente de disputa territorial centrada en la capacidad estatal y la desigualdad de la tierra. Contrariamente a otras hipótesis, sugerí que la producción de desigualdad de tierras aumenta la capacidad local del estado y que tanto los agravios generados en el proceso de creación de desigualdad, como las oportunidades proporcionadas por el tipo de presencia estatal aumentan las posibilidades de disputa territorial. Un análisis cuantitativo de 194 localidades proporcionó un apoyo sustancial a esta teoría. La desigualdad de la tierra está correlacionada con una mayor capacidad estatal, y esta, según los datos, tiene una relación en forma de $\mathrm{U}$ invertida con la disputa territorial. Por último, los efectos de la desigualdad de la tierra en la disputa territorial dependen en gran medida de la capacidad del estado local.

La sección empírica de este artículo ofreció evidencia contrastante con otras explicaciones rivales. A pesar de que otros autores han encontrado una fuerte evidencia del papel de los diferentes recursos en la presencia de los actores armados, los recursos incluidos — coca, regalías y transferencias - no están fuertemente vinculados con la disputa territorial. Los recursos pueden ser un gran predictor a la llegada del actor armado, pero no de disputa territorial. 


\section{8 / Silvia Otero Bahamón}

Este artículo también proporcionó nuevos elementos para un debate recurrente en la literatura del conflicto. Varios autores del conflicto colombiano llegaron a la conclusión de que, aunque los agravios jugaron un papel importante en los primeros años de este, desde la década de 1980 los actores armados han sido impulsados por motivos codiciosos o estratégicos (Echandía, 1999; Sánchez \& Chacón, 2006). Mi evidencia sugiere que esta conclusión es incorrecta. Procesos políticos y económicos que tienden a producir agravios, tales como la desigualdad rural, juegan un papel determinante en la dinámica de la disputa territorial. La concentración de la tierra podría crear clivajes que atraen a diferentes actores armados, lo que resultaría en disputas. En este sentido, el estado debe evitar que los esfuerzos de construcción estatal produzcan desigualdad rural.

Este documento tiene implicaciones políticas interesantes. Hasta ahora, la estrategia del estado colombiano para luchar contra la guerrilla ha sido el despliegue militar y la expansión estatal en áreas donde la guerrilla tiene sus fortalezas - aunque con muchas limitaciones-. Sin embargo, este documento muestra dos advertencias con respecto a esta estrategia. Primero, las estrategias adicionales de formación estatal en lugares donde el estado está semipresente podrían ayudar a superar el límite en el que los rebeldes disputan localidades. Al realizar esfuerzos adicionales de formación estatal en áreas de capacidad estatal intermedia, el estado podría volcar el equilibrio de poder a su favor y evitar que los territorios se disputen territorialmente. En segundo lugar, las estrategias de formación del estado en lugares donde este no está presente podrían eliminar efectivamente las retaguardias de los rebeldes en estas regiones, pero también podrían aumentar las posibilidades de disputa territorial entre los diferentes actores armados, incluidos los grupos paramilitares. Como vimos en el caso de la desigualdad rural, la transición de una presencia estatal baja a una intermedia puede crear divisiones, incentivos y oportunidades que estimulan la disputa territorial. En conclusión, las estrategias de construcción estatal pueden aumentar la violencia en algunas regiones y reducirla en otras. 


\section{Referencias}

Arjona, A. (2016a). Rebelocracy: Social order in the Colombian civil war. Cambridge University Press.

Arjona, A. (2016b). Institutions, civilian resistance, and wartime social order: A process-driven natural experiment in the Colombian civil war. Latin American Politics and Society, 58(3), 99-122. https://doi.org/10.1111/ j.1548-2456.2016.00320.x

Aponte González, A. F. (2019). Grupos armados y construcción de orden social en la esquina sur del Tolima, 1948-2016. CINEP - Programa por la Paz: Educapaz - Pontificia Universidad Javeriana Cali.

Balcells, L., Kalyvas, S. N. (2014). Does warfare matter? Severity, duration, and outcomes of civil wars. Journal of Conflict Resolution, 58(8), 13901418. https://doi.org/10.1177/0022002714547903

Bottia, M. (2003). La presencia y expansión municipal de las FARC; es avaricia y contagio más que ausencia estatal. Documentos CEDE (2003-03). http:/ /hdl.handle.net/1992/8258http://econpapers.repec.org/paper/ col000089/003060.htm

Boulding, K. E. (1962). Conflict and defense: A general theory. Harper \& Brothers. http:/ / doi.apa.org/?uid=1963-00981-000

Buhaug, H., \& Rød, J. K. (2006). Local determinants of African civil wars, 1970-2001. Political Geography, 25(3), 315-335. https://doi. org/10.1016/j.polgeo.2006.02.005

Buhaug, H., Gates, S., \& Lujala, P. (2009). Geography, rebel capability, and the duration of civil conflict. Journal of Conflict Resolution, 53(4), 544569. https://doi.org/10.1177/0022002709336457

Buhaug, H., Gleditsch, K. S., Holtermann, H., Østby, G., \& Tollefsen, A. F. (2011). It's the local economy, stupid! Geographic wealth dispersion and conflict outbreak location. The Journal of Conflict Resolution, 55(5), 814-840.

Collier, P. (2000a). Doing well out of war: An economic perspective in greed and grievance. En M. Berdal, \& M. Malone (eds.), Greed and grievance. Economic agendas in civil wars (pp. 91-111). Lynne Reinner. https:// idl-bnc-idrc.dspacedirect.org/bitstream/handle/10625/23397/IDL23397.pdf? sequence $=1$ \&is Allowed $=y$

Collier, P. (2000b). Rebellion as a quasi-criminal activity. Journal of Conflict Resolution, 44(6), 839-853. https:/ / doi.org/10.1177/0022002700044006008 
Collier, P., \& Hoeffler, A. (2004). Greed and grievance in civil war. Oxford Economic Papers, 56(4), 563-595. https://doi.org/10.1093/oep/gpf064

Cramer, C. (2005). Inequality and conflict: A review of an age-old concern. Identities, Conflict and Cohesion Programme Paper, (11), 1-26. http:/ / www. unrisd.org/UNRISD/website/document.nsf/0/0501D4F6B30830 76C12570B4004F0D5B? OpenDocument\&language $=\mathrm{fr}$

Ciro Rodríguez, E. (2019). Levantados de la selva: Vidas y legitimidades en los territorios cocaleros del Caquetá. Ediciones Uniandes.

Duncan, G. (2015). Los señores de la guerra. Debate.

Echandía, C. (1998). El conflicto armado y las manifestaciones de violencia en las regiones de Colombia (Vol. 1). Presidencia de la República, Oficina del Alto Comisionado para la paz, Observatorio de la Violencia.

Fearon, J. D., \& Laitin, D. D. (2003). Ethnicity, insurgency, and civil war. American Political Science Review, 97(1), 75-90. https://doi.org/10.1017/ S0003055403000534

Gilmore, E., Gleditsch, N. P., Lujala, P., \& RØd, J. K. (2005). Conflict diamonds: A new dataset. Conflict Management and Peace Science, 22(3), 257-272. https://doi.org/10.1080/07388940500201003

Goertz, G. (2006). Social science concepts: A user's guide. Princeton University Press. González, F. E., Bolívar, I. J., \& Vázquez, T. (2003). Violencia política en Colombia: De la nación fragmentada a la construcción del Estado. Centro de Investigación y Educación Popular.

González, F. E. (2011). A manera de síntesis conclusiva. En T. Vásquez, A. R. Vargas, \& A. J. Restrepo (Eds.), Una vieja guerra en un nuevo contexto: Conflicto y territorio en el sur de Colombia. Odecofi - CINEP.

González, F. E. (2014). Poder y violencia en Colombia. Odecofi - CINEP.

Granada, S., \& Sánchez-Meertens, C. (2009). Correlación de fuerzas en disputas de guerras civiles: una aplicación al caso colombiano. En J. Restrepo, \& D. Aponte (Eds.), Guerra y violencias en Colombia: herramientas e interpretaciones. Editorial Pontificia Universidad Javeriana.

Grupo de Memoria Histórica. (2013). jBasta ya! Colombia: Memorias de guerra y dignidad. Centro Nacional de Memoria Histórica.

Hammond, J. (2018). Maps of mayhem: Strategic location and deadly violence in civil war. Journal of Peace Research, 55(1), 32-46. https://doi. org/10.1177/0022343317702956 
Hegre, H., \& Sambanis, N. (2006). Sensitivity analysis of empirical results on civil war onset. Journal of Conflict Resolution, 50(4), 508-535. https:// doi.org/10.1177/0022002706289303

Hegre, H., Østby, G., \& Raleigh, C. (2009). Poverty and civil war events: A disaggregated study of Liberia. Journal of Conflict Resolution, 53(4), 598-623.

Hendrix, C. S. (2011). Head for the hills? Rough terrain, state capacity, and civil war onset. Civil W ars, 13(4), 345-370. https:/ / doi.org/10. 1080/13698249.2011.629863

Herbst, J. (2000). States and power in Africa: Comparative lessons in authority and control. Princeton University Press.

Humphreys, M., \& Weinstein, J. M. (2006). Handling and manhandling civilians in civil war. American Political Science Review, 100(3), 429-447. https:/ / doi.org/10.1017/S0003055406062289

Huntington, S. (1968). Political order in changing societies. Yale University Press. Kalmanovitz, S. (2001). Las instituciones y el desarrollo económico en Colombia. Editorial Norma.

Kalyvas, S. N. (2006). The logic of violence in civil war. Cambridge University Press.

Kalyvas, S. N., \& Balcells, L. (2010). International system and technologies of rebellion: How the end of the cold war shaped internal conflict. American Political Science Review, 104(3), 415-429. https: / / doi.org/10.1017/ S0003055410000286

Mampilly, Z. C. (2011). Rebel rulers: Insurgent governance and civilian life during war. Cornell University Press.

Metelits, C. (2009). Inside insurgency: Violence, civilians, and revolutionary group behavior. New York University Press.

Montenegro, A., \& Posada, C. E. (1994). Criminalidad en Colombia (No. 4; Borradores Semanales de Economía). Banco de la República, Subgerencia de Estudios Económicos. https://www.banrep.gov.co/es/ criminalidad-colombia-borrador-economia

Museo Casa de la Memoria \& Reyes, A. (2015). Una mirada múltiple a la tierra y la violencia en Colombia [Insumo para los textos de la exposición Colombia. Paraíso despojado]. Medellín: Museo Casa de la Memoria - Alcaldía de Medellín.

Ocampo, G. I. (2007). La instauración de la ganadería en el valle del Sinú: La hacienda Marta Magdalena, 1881-1956. Universidad de Antioquia. 
Østby, G. (2013). Inequality and political violence: A review of the literature. International Area Studies Review, 16(2), 206-231. https:/ doi. org/10.1177/2233865913490937

Pécaut, D. (2001). Orden y violencia: Evolución socio-politica de Colombia entre 1930 y 1953. Editorial Norma.

Peñate, A. (1999). El sendero estratégico del ELN: del idealismo guevarista al clientelismo armado. En M. Deas \& M. V. Llorente (Eds.), Reconocer la guerra para construir la paz. (pp. 53-98). Uniandes.

Peñaranda Currie, I., Otero-Bahamon, S., \& Uribe, S. (2021). What is the state made of? Coca, roads, and the materiality of state formation in the frontier. World Development, 141, 105395. https://doi.org/10.1016/j. worlddev.2021.105395

Raleigh, C., \& Hegre, H. (2009). Population size, concentration, and civil war. A geographically disaggregated analysis. Political Geography, 28(4), 224-238. https://doi.org/10.1016/j.polgeo.2009.05.007

Reyes, A. (1978). Latifundio y poderpolitico. La hacienda ganadera en Sucre. CINEP.

Rettberg, A., \& Ortiz-Riomalo, J. F. (2016). Golden opportunity, or a new twist on the resource - conflict relationship: Links between the drug trade and illegal gold mining in Colombia. World Development, 84, 8296. https://doi.org/10.1016/j.worlddev.2016.03.020

Ross, M. L. (2004). What do we know about natural resources and civil war? Journal of Peace Research, 41(3), 337-356. https://doi. org/10.1177/0022343304043773

Rubio, M. (2002). Conflicto y finanzas públicas municipales en Colombia. Documento CEDE, (2002-17). http:/ / hdl.handle.net/1992/8203

Rustad, S. C. A., Rød, J. K., Larsen, W., \& Gleditsch, N. P. (2008). Foliage and fighting: Forest resources and the onset, duration, and location of civil war. Political Geography, 27(7), 761-782.

Sánchez, F., \& Chacón, M. (2006). Conflicto, Estado y descentralización: Del progreso social a la disputa armada por el control local. En F. G. Gutierrez \& M. E. Wills (Eds.), Nuestra guerra sin nombre: Transformaciones del conflicto en Colombia (pp. 196-236). IEPRI - Editorial Norma.

Saffon M.P., \& Sánchez, F. (2019). Historical grievances and war dynamics: old land conflicts as a cause of current forced displacements in Colombia. Documento CEDE (2019-21). http:/ / hdl.handle.net/1992/41085 
Soifer, H., \& Hau, M. vom. (2008). Unpacking the strength of the state: The utility of state infrastructural power. Studies in Comparative International Development, 43(3-4), 219. https:/ / doi.org/10.1007/s12116-008-9030-z

Tao, R., Strandow, D., Findley, M., Thill, J.-C., \& Walsh, J. (2016). A hybrid approach to modeling territorial control in violent armed conflicts. Transactions in GIS, 20(3), 413-425. https:/ / doi.org/10.1111/tgis.12228

Tollefsen, A. F., \& Buhaug, H. (2015). Insurgency and inaccessibility. International Studies Review, 17(1), 6-25. https:/ / doi.org/10.1111/misr.12202

Van Leeuwen, M., \& Van Der Haar, G. (2016). Theorizing the landViolent conflict nexus. World Development, 78, 94-104. https://doi. org/10.1016/j.worlddev.2015.10.011

Vásquez, T. (2018). Territorios, conflicto armado y política en el Caquetá: 1900-2010: Cambio ambientaly movilidad humana en Colombia. Ediciones Uniandes.

Vásquez, T., Vargas, A. R., \& Restrepo, J. A. (2011). Una vieja guerra en un nuevo contexto: Conflicto y territorio en el sur de Colombia. Odecofi - CINEP.

Vélez, M. A. (2001). FARC-ELN: Evolución y expansión territorial. Desarrollo y Sociedad, (47), 151-225. https://doi.org/10.13043/dys.47.4

Walter, B. F. (1997). The critical barrier to civil war settlement. International Organization, 51(3), 335-364. https://doi.org/10.1162/002081897550384

Wang, X. (2014). Firth logistic regression for rare variant association tests. Frontiers in Genetics, 5, 187.

Weinstein, J. M. (2006). Inside rebellion: The politics of insurgent violence. Cambridge University Press.

Zhukov, Y. M. (2012). Roads and the diffusion of insurgent violence: The logistics of conflict in Russia's North Caucasus. Political Geography, 31(3), 144-156. https://doi.org/10.1016/j.polgeo.2011.12.002 


\section{Apéndice 1. Reglas de codificación para disputas territoriales}

\section{Hostilidades}

\begin{tabular}{|l|c|}
\hline \multicolumn{1}{|c|}{ Hostilidades } & Puntos \\
\hline Combates & 3 \\
\hline Emboscadas & 3 \\
\hline Bombardeos & 3 \\
\hline Ataque a objetivo militar & 3 \\
\hline Sabotaje & 3 \\
\hline Asalto & 2 \\
\hline
\end{tabular}

Victimización civil

\begin{tabular}{|l|c|}
\hline \multicolumn{1}{|c|}{ Victimización civil } & Puntos \\
\hline Masacre (o desaparición forzada colectiva) de 4 o 5 víctimas & 3 \\
\hline Masacre (o desaparición forzada colectiva) de más de 5 víctimas & 5 \\
\hline Masacres con otras violaciones (saqueo, desplazamiento forzado) & 7 \\
\hline Desplazamiento forzado colectivo & 3 \\
\hline Homicidio & 1 \\
\hline Desaparición forzada & 1 \\
\hline Ataque indiscriminado & 2 \\
\hline Saqueo & 1 \\
\hline
\end{tabular}




\section{Apéndice 2. Muestra municipal y distribución de municipios con disputa territorial}

\begin{tabular}{|c|c|c|c|c|c|c|}
\hline 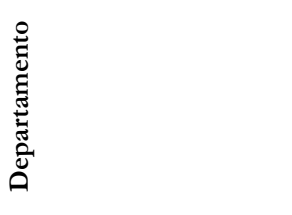 & 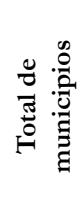 & 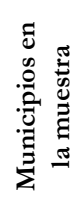 & 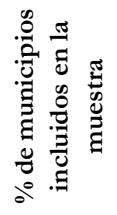 & 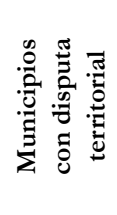 & 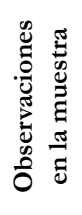 & 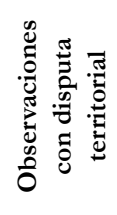 \\
\hline Amazonas & 11 & 0 & 0,0 & 0 & 0 & 0 \\
\hline Antioquia & 126 & 21 & 16,7 & 6 & 105 & 12 \\
\hline Arauca & 7 & 3 & 42,9 & 3 & 15 & 9 \\
\hline Atlántico & 23 & 5 & 21,7 & 0 & 25 & 0 \\
\hline Bolívar & 45 & 5 & 11,1 & 1 & 25 & 2 \\
\hline Boyacá & 123 & 22 & 17,9 & 0 & 110 & 0 \\
\hline Caldas & 27 & 5 & 18,5 & 0 & 25 & 0 \\
\hline Caquetá & 16 & 4 & 25,0 & 1 & 20 & 1 \\
\hline Casanare & 19 & 4 & 21,1 & 2 & 20 & 2 \\
\hline Cauca & 41 & 8 & 19,5 & 5 & 40 & 10 \\
\hline Cesar & 25 & 6 & 24,0 & 2 & 30 & 4 \\
\hline Córdoba & 30 & 6 & 20,0 & 2 & 30 & 4 \\
\hline Chocó & 31 & 2 & 6,5 & 0 & 10 & 0 \\
\hline Cundinamarca & 116 & 26 & 22,4 & 3 & 130 & 3 \\
\hline Guainía & 9 & 0 & 0,0 & 0 & 0 & 0 \\
\hline Guaviare & 4 & 1 & 25,0 & 1 & 5 & 1 \\
\hline Huila & 37 & 6 & 16,2 & 2 & 30 & 5 \\
\hline La Guajira & 15 & 5 & 33,3 & 2 & 25 & 2 \\
\hline Magdalena & 30 & 6 & 20,0 & 1 & 30 & 2 \\
\hline Meta & 29 & 7 & 24,1 & 3 & 35 & 4 \\
\hline Nariño & 64 & 8 & 12,5 & 1 & 40 & 1 \\
\hline Norte de Santander & 40 & 5 & 12,5 & 2 & 25 & 5 \\
\hline Putumayo & 13 & 0 & 0,0 & 0 & 0 & 0 \\
\hline Quindío & 12 & 1 & 8,3 & 0 & 5 & 0 \\
\hline Risaralda & 14 & 1 & 7,1 & 1 & 5 & 4 \\
\hline San Andres y Providencia & 2 & 0 & 0,0 & 0 & 0 & 0 \\
\hline Santander & 87 & 14 & 16,1 & 1 & 70 & 1 \\
\hline Sucre & 26 & 4 & 15,4 & 1 & 20 & 4 \\
\hline Tolima & 47 & 11 & 23,4 & 1 & 55 & 1 \\
\hline Valle del Cauca & 42 & 6 & 14,3 & 0 & 30 & 0 \\
\hline Vaupes & 3 & 0 & 0,0 & 0 & 0 & 0 \\
\hline Vichada & 4 & 2 & 50,0 & 0 & 10 & 0 \\
\hline
\end{tabular}

